\title{
Dynamic Complexities in a Supply Chain System with Lateral Transshipments
}

\author{
Yongchang Wei $(\mathbb{D}$, Fangyu Chen $(\mathbb{D}$, and Feng Xiong \\ Institute of Operations Management and System Engineering, School of Business Administration, \\ Zhongnan University of Economics and Law, Wuhan 430073, China
}

Correspondence should be addressed to Fangyu Chen; cfyconan@126.com

Received 22 June 2017; Revised 28 February 2018; Accepted 26 March 2018; Published 25 June 2018

Academic Editor: Dimitri Volchenkov

Copyright (C) 2018 Yongchang Wei et al. This is an open access article distributed under the Creative Commons Attribution License, which permits unrestricted use, distribution, and reproduction in any medium, provided the original work is properly cited.

\begin{abstract}
The horizontal interaction between retailers, coupled with replenishment rules and time delays, makes the dynamics in supply chain systems highly complicated. This paper aims to explore the impacts of lateral transshipments on the stability, bullwhip effect, and other performance measurements in the context of a two-tiered supply chain system composed of one supplier and two retailers. In particular, we developed a unified discrete-time state space model to address two different scenarios of placing orders. Analytical stability results are derived, through which we found that inappropriate lateral transshipment policies readily destabilize the supply chain system. Moreover, the lead time of lateral transshipments further complicates the stability problem. Theoretical results are validated through simulation experiments and the influences of system parameters on performance measures are investigated numerically. Numerical simulations show that lateral transshipments help improve the customer service level for both retailers. It is also interesting to observe that the demand of the two retailers can be satisfied even if only one retailer places orders from the upstream supplier.
\end{abstract}

\section{Introduction}

The dynamics of a supply chain system has grown increasingly complicated due to numerous factors, such as global economic downturn, e-commerce development, and disruptive events. These factors bring great challenges to supply chain management in uncertain environments. In uncertain conditions, it is usually very hard to derive analytically optimal policies in maximizing the benefits for the whole supply chain system over a long duration. However, understanding how different factors affect the dynamic complexities of supply chain systems will be very useful for guiding the selection of parameters. To deal with demand variability and reduce the risk of stock-out, one of the options is to implement collaborative programs between supply chain members by exploiting advanced information technologies, such as Vendor Managed Inventory (VMI) and Collaborative Planning Forecasting and Replenishment (CPFR) [1,2]. In contrast to those collaborative programs in which items are moved from upstream to downstream, members in the same echelon may redistribute or pool a fraction of inventory to mitigate the risks in demand fulfillment. Lateral transshipment is such a program for distributing goods or services between sources, storage points, and destinations to cope with demand fluctuations [3]. However, lateral transshipments enhance the horizontal interaction between supply chain members and thus complicate the structure and function of supply chain systems $[3,4]$. Due to the these reasons, this paper addresses the dynamic complexities in a supply chain system with lateral transshipments between two retailers from the perspective of complex systems.

The benefits of lateral transshipments have been well discussed, such as reducing inventory cost and improving customer service level [5-7]. In addition, lateral transshipments enhance the system resilience of supply chain systems in the presence of disruptions due to inventory pooling $[8,9]$. In practice, collaboration programs with lateral transshipments have been implemented in numerous areas, such as retail, the energy industry, and the automotive industry $[10,11]$. Automotive dealers routinely share parts so that they can promptly complete the repairing of their customers' vehicles. Lateral transshipments can be either restricted to take place at 
predetermined times before all demand is realized or at any time to respond to stock-outs. We refer to the first type of lateral transshipment as proactive transshipment, while the second type is referred to as reactive transshipment [3]. The proactive lateral transshipments are arranged in advance to redistribute stock amongst all stocking points such that the handling costs are as low as possible. The reactive transshipments may be costly or too late to redistribute products in selling products, since they only meet the immediate shortfall and ignore the risk of future shortages [7]. In this paper, we focus on the proactive lateral transshipments.

The majority of the existing literatures on lateral transshipments have hitherto focused on deriving optimal or suboptimal transshipment policies as well as replenishment decisions under specific assumptions [6,12-15]. The methods in the literature can be mainly grouped into four classes: mathematical programming $[7,12,16]$, game theory, queuing theory [17], and simulation experiments [18]. The strict assumptions underlying these models may impede their implementation. For example, the results in most of the existing literature are derived based on specific demand models, such as a certain type of probability distribution or time series process $[4,19]$. Realistic demand, however, is highly uncertain due to a lot of factors, including promotion activities, economic crisis, and political events. Inventory models with more realistic assumptions are difficult to analyze or solve. In contrast, dynamic system theories can be very useful because they focus on the impacts of system structure on dynamic behaviors, which are closely related to system performance.

Actually, a supply chain system is a dynamical system by nature, because its inventory and order fluctuate over time. The dynamics of supply chain systems, such as the bullwhip effect [20-23], stability [24-28], and chaos [2931], have received extensive attention over the past decades. Accordingly, the impacts of the interactions between members on supply chain dynamics have likewise begun to attract academic attention. For example, [30] investigated the interaction caused by the price discount strategies between customers and suppliers in a three-tier supply chain system. Reference [31] studied the interaction between retailers and customers, in which the customer demand is stimulated by the inventories displayed by retailers. The previous research shows that the interactions between upstream and downstream members make the dynamics of supply chain systems very complicated. However, to the best of our knowledge, no research has addressed the impact of the horizontal interactions between the members in the same echelon, for example, lateral transshipment, on dynamic complexities.

To bridge the aforementioned gap, this paper focuses on exploring the dynamic complexities in a supply chain system with lateral transshipments between two retailers. Specifically, we focus on how the vertical replenishment policy and horizontal lateral transshipment policy affect the fluctuations of inventory and order. We derived the stability conditions for the supply chain system in two different scenarios. In the first scenario, each of the two retailers places orders from the upstream supplier. In the second scenario, only one retailer assumes the task of placing orders.
This scenario is motivated by our real-life observations in both electrical and PC retail industries in China. To reduce the ordering cost, stock-out cost, and inventory holding cost, the retailers in such industries may satisfy customer demand just by lateral transshipments from nearby retailers without placing orders with upstream suppliers. This scenario can be very effective in reducing inventories and occurs frequently in two situations: either a retailer attempts to sell new products or customers want to buy new products but their retailer does not have temporarily. The most critical contribution of this research lies in our provision of both delay-dependent and delay independent stability conditions through analytical study, from which we show that lateral transshipments make the dynamics of supply chain systems more complicated. These theoretical results are significant for the selection of both replenishment parameters and later transshipment parameters in achieving better performance. Through simulation experiments, we demonstrate the advantages of lateral transshipments in improving demand satisfaction and mitigating the bullwhip effect. Furthermore, an interesting observation is that both retailers can better fulfill customer demand even when one of them places orders from the upstream supplier. The derived results are helpful in providing general guidelines on system planning and operation.

The structure of this paper is organized as follows. In Section 2, a unified state model is developed and some key measurements are introduced for conducting the simulation experiments in Section 4. Section 3 analyzes the steady values of system states and derives analytical stability results, which are validated by the simulation experiments in Section 4 . Furthermore, based on the stability results, the impacts of lateral transshipments on system performance are investigated and some managerial insights are drawn. The paper is concluded with Section 5.

\section{Model Description}

2.1. A State Space Model. Consider a two-echelon supply chain system comprised of one external supplier and two retailers with lateral transshipments. The structure of the supply chain system is depicted by Figure 1. Without loss of generality, we assume that the two retailers periodically review their inventory at weekly or monthly intervals. The review period may be one week or one month. To make the model linear, we assume that the supply capacity of the upstream supplier is unlimited. This assumption, which is frequently made in the literature [31,32], is reasonable because the external supplier represents all the possible supply sources.

During each period $t \in\{1,2,3, \ldots\}$, the two retailers control their inventory following a sequence of events described as follows. (1) At the beginning of each period, the two retailers receive shipments from the supplier, which is the order placed in the previous period. (2) After that, they place orders from the upstream supplier based on demand forecasting and then transfer the inventory in accordance with a predetermined lateral transshipment contract. (3) During the remaining time of each period, the two retailers 


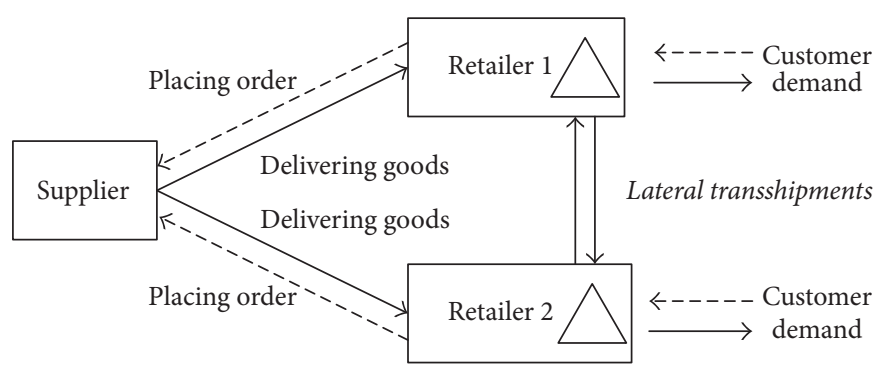

FIGURE 1: The structure of a supply chain system with lateral transshipments.

satisfy their customer demands and the unsatisfied demands are backlogged to the next period.

We consider two different scenarios in our model: scenario $\xi_{1}$ and scenario $\xi_{2}$, where $\xi_{1}$ represents the scenario that two retailers place orders with the upstream supplier independently and $\xi_{2}$ represents the situation in which only one retailer places orders with the upstream supplier and the demand of other retailers is satisfied by only lateral transshipments. The study of the second scenario $\xi_{2}$ is motivated by our observations in electrical and PC retail industries in China. This scenario occurs in two situations: firstly, a retailer attempts to sell a specific new product due to potential market demand but he or she is not very familiar with the purchasing channels; secondly, a customer may place an order containing a collection of items from a retailer, but some items are outside the selling list of the retailer [7]. To save the time in purchasing the items from different retailers, the customer may authorize a retailer to purchase all the items. In both situations, the retailer can use lateral transshipments to gain more profits and avoid customer loss. The main advantage for the second scenario lies in the reduction of ordering cost and inventory cost.

For simplicity, we assume that the replenishment lead time for the two retailers to place orders with the upstream supplier is only one period. We assume that lateral transshipments incur a fixed lead time of $\tau$ periods. Although some papers concerning lateral transshipments assume negligible transshipment lead times [33], the real-life lateral transshipment lead times may be nonnegligible due to information processing time and the objective of reducing transaction costs $[15,18]$. In addition, we aim at disclosing how the lead time in lateral transshipment affects dynamic complexities and system performance. It is well known that the dynamics of time-delayed systems is highly complicated [25, 34, 35]. The notations used in this study are listed in the Main Notations and Symbols section.

We shall firstly develop a state space model based on difference equations corresponding to the event sequence introduced before. We use $i \in\{1,2\}$ to index the $i$ th retailer. The difference equation for reviewing the inventory level is represented as

$$
I_{i}(t+1)=I_{i}(t)+O_{i}(t)+L_{i}(t)-D_{i}(t),
$$

where $I_{i}(t)$ is the inventory level, $D_{i}(t)$ is the customer demand, and $L_{i}(t)$ is the amount of lateral transshipment received by retailer $i$. The sign of $L_{i}(t)$ indicates the direction of the inventory movement. It always satisfies $\operatorname{sign}\left(L_{1}(t) L_{2}(t)\right)=-1$ or $\operatorname{sign}\left(L_{1}(t) L_{2}(t)\right)=0$, in which

$$
\operatorname{sign}(x)= \begin{cases}1 & \text { if } x>0, \\ 0 & \text { if } x=0, \\ -1 & \text { if } x<0 .\end{cases}
$$

Consequently, the amount of lateral transshipments from retailer $j$ to retailer $i(i \neq j)$ is determined by

$$
L_{i}(t)=\varphi_{L}\left[I_{j}(t-\tau)-I_{i}(t-\tau)\right],
$$

in which $\varphi_{L}$ is the parameter to determine the magnitude of lateral transshipments. Specifically, there are no lateral transshipments between the two retailers if $\varphi_{L}=0$. Conversely, the two retailers fully swap their inventory with $\varphi_{L}=1$. Thus, we can make the assumption $0 \leq \varphi_{L} \leq 1$.

Due to its excellence in short-term predictions [27], the two retailers employ the exponential smoothing algorithm to predict the demand for each coming period, which is represented as

$$
F_{i}(t+1)=F_{i}(t)+\theta_{i}\left[D_{i}(t)-F_{i}(t)\right],
$$

where $F_{i}(t)$ is the predictive amount and the parameter $\theta_{i}$ is the smoothing coefficient. The smoothing coefficient should be determined by the characteristics of customer demand. For example, small values of $\theta_{i}$ are appropriate for stationary demand, while large values may be better to respond to volatile demand [25].

The replenishment rule is one of the core factors underlying system performance. In general, inventory decisions should be made accounting for demand trend, on-hand inventory, stock-out, and pipeline stock. In our model, however, there is no pipeline stock because we assume that replenishment lead time is only one period. Thus, the inventory rule is viewed as a function of demand forecast and inventory level. The inventory polices corresponding to the aforementioned two scenarios are quite different.

Recall that the two retailers assume their tasks of placing orders independently in the first scenario, while only retailer 1 places order with the upstream supplier in the second scenario. In the first scenario, the inventory policy for the two retailers is represented as

$$
O_{i}(t)=F_{i}(t)+\rho_{i}\left[I_{i}^{T}-I_{i}(t)\right],
$$


where $\rho_{i}$ is the replenishment parameter and $I_{i}^{T}$ is the inventory target. This inventory policy can be understood as a feedback controller to restock the inventory level to its target level. Thus, with a large $\rho_{i}$, the retailer's inventory can rapidly respond to customers, while the parameter $I_{i}^{T}$ should be optimized to balance the trade-off between inventory cost and customer service.

In the second scenario, only retailer 1 makes replenishment decisions based on the systematic inventory, which is the sum of the two retailers' inventory levels: $\mathrm{SI}(t)=I_{1}(t)+$ $I_{2}(t)$. Correspondingly, the inventory policy for retailer 1 is represented as

$$
O_{1}(t)=F_{1}(\mathrm{t})+F_{2}(t)+\rho\left[\mathrm{SI}^{T}-\mathrm{SI}(t)\right]
$$

in which $\rho$ is still a replenishment parameter and $\mathrm{SI}^{T}$ is the target of system inventory. It is noteworthy that retailer 2 does not place any orders and therefore $\mathrm{O}_{2}(t)=0$.

Based on the above difference equations, we develop a unified state model for the two scenarios by substituting the inventory policies (5) or (6) into the balanced inventory equation (1). Define $\mathbf{x}(t)=\left[F_{1}(t), F_{2}(t), I_{1}(t), I_{2}(t)\right]^{\prime}$ as the state vector and $\mathbf{w}(t)=\left[D_{1}(t), D_{2}(t)\right]^{\prime}$ as the input vector. Denote $\mathcal{S}=\left\{\xi_{1}, \xi_{2}\right\}$ as the set of scenarios. Then, a unified state space model is developed as

$$
\mathbf{x}(t+1)=\mathbf{A}_{\xi} \mathbf{x}(t)+\mathbf{B}_{\xi} \mathbf{x}(t-\tau)+\mathbf{C}_{\xi} \mathbf{w}(t)+\mathbf{D}_{\xi},
$$

in which $\xi \in \mathcal{S}$ and

$$
\begin{aligned}
\mathbf{A}_{\xi_{1}} & =\left[\begin{array}{cccc}
1-\theta_{1} & 0 & 0 & 0 \\
0 & 1-\theta_{2} & 0 & 0 \\
1 & 0 & 1-\rho_{1} & 0 \\
0 & 1 & 0 & 1-\rho_{2}
\end{array}\right], \\
\mathbf{A}_{\xi_{2}} & =\left[\begin{array}{cccc}
1-\theta_{1} & 0 & 0 & 0 \\
0 & 1-\theta_{2} & 0 & 0 \\
1 & 1 & 1-\rho & -\rho \\
0 & 0 & 0 & 1
\end{array}\right], \\
\mathbf{B}_{\xi_{1}} & =\mathbf{B}_{\xi_{2}}=\left[\begin{array}{cccc}
0 & 0 & 0 & 0 \\
0 & 0 & 0 & 0 \\
0 & 0 & -\varphi_{L} & \varphi_{L} \\
0 & 0 & \varphi_{L} & -\varphi_{L}
\end{array}\right] \\
\mathbf{C}_{\xi_{1}} & =\mathbf{C}_{\xi_{2}}=\left[\begin{array}{cc}
\theta_{1} & 0 \\
0 & \theta_{2} \\
-1 & 0 \\
0 & -1
\end{array}\right],
\end{aligned}
$$

$$
\begin{gathered}
\mathbf{D}_{\xi_{1}}=\left[\begin{array}{c}
0 \\
0 \\
\rho_{1} I_{1}^{T} \\
\rho_{2} I_{2}^{T}
\end{array}\right], \\
\mathbf{D}_{\xi_{2}}=\left[\begin{array}{c}
0 \\
0 \\
\rho \mathrm{SI}^{T} \\
0
\end{array}\right] .
\end{gathered}
$$

2.2. Performance Measurements. Lateral transshipments critically affect the system performance by taking role in redistribution of inventory to the retailers. In this research, we will consider the average total inventory cost (TIC), average total ordering cost (TOC), average lateral transshipment cost (LC), customer service level for the two retailers $\left(\mathrm{SL}_{i}\right)$, and the bullwhip effect metric (BW). In the following, we shall define these measurements.

The average total inventory cost (TIC), composed of inventory holding cost and stock-out cost, is represented as

TIC

$$
=\frac{\sum_{i=1}^{2} \sum_{t=1}^{N}\left\{c_{h}\left[I_{i}(t)-D_{i}(t)\right]^{+}+c_{b}\left[I_{i}(t)-D_{i}(t)\right]^{-}\right\}}{N},
$$

where $c_{h}$ is the holding cost per unit, $c_{b}$ is the stock-out cost per unit, and $N$ is the simulation length.

The average ordering cost for the supply chain system is computed by

$$
\mathrm{TOC}=\frac{\sum_{i=1}^{2} \sum_{t=1}^{N} c_{o}\left|O_{i}(t)\right|}{N},
$$

where $c_{o}$ is the ordering cost per unit.

The average lateral transshipment cost for the two retailers is obtained by

$$
\mathrm{LC}=\frac{\sum_{t=1}^{N} c_{l}\left|L_{1}(t)\right|}{N},
$$

where $c_{l}$ is the lateral transshipment cost per unit. In contrast to $c_{o}, c_{l}$ is relatively small because lateral transshipments take place between two retailers in geographical proximity.

By using the sign function introduced previously, the service level for the two retailers is defined as

$$
\mathrm{SL}_{i}=1-\frac{\sum_{t=1}^{N} \operatorname{sign}\left(\left[D_{i}(t)-I_{i}(t)\right]^{+}\right)}{N} .
$$

The sign function is employed to record the period number of stock-outs. It means that we can increase the service level for the two retailers if we can satisfy the customer demand in most of the simulation periods.

The bullwhip effect refers to the amplification of demand fluctuations as one moves up a supply chain from downstream to upstream [25]. In this research, we study the 
bullwhip effect because the redistribution of inventory may alter the ordering behavior. For our model, the bullwhip effect can be measured by the ratio of order variance to demand variance [36], which is represented as

$$
\mathrm{BW}=\frac{\sum_{i=1}^{2} \operatorname{var}\left(O_{i}\right)}{\sum_{i=1}^{2} \operatorname{var}\left(D_{i}\right)},
$$

where var $\left(O_{i}\right)$ and $\operatorname{var}\left(D_{i}\right)$ represent the order variance and inventory variance of retailer $i$, respectively.

\section{Dynamics Analysis}

In this section, we analyze the dynamic complexities of the state space model (7) in two scenarios $\xi_{1}$ and $\xi_{2}$ with the following two steps.

Step 1. Analyze the steady states of the inventories of the two retailers, which essentially determine the equilibrium points due to the interaction between supply chain members [37]. The results of the steady state analysis are important for determining the parameters of the desirable system. However, such analysis is applicable to only stable systems because unstable system exhibits divergent behaviors.

Step 2. Derive the stability conditions for the two scenarios. As investigated in the literature, stability is a fundamental problem for any dynamic systems including inventory systems $[24,25,38]$. Upon disruption, a stable system will gradually return to its steady state. By contrast, unstable designs will cause undesirable fluctuations for order and inventory, which leads to high cost due to inventory accumulation or stock-outs. Consequently, stability analysis provides a foundation for the determination of parameters and performance optimization.

3.1. Steady State Analysis. Without loss of generality, we assume that the steady states of the demands of the two retailers are expressed as $D_{i}^{\infty}, i \in\{1,2\}$, which are understood as the mean values of customer demands, because demands usually fluctuate around them. Denote the steady states of inventory level and of the order quantity as $I_{i}^{\infty}$ and $O_{i}^{\infty}$, respectively.

Firstly, consider the scenario $\xi=\xi_{1}$ in which each of the two retailers places order with the upstream supplier independently. According to the inventory balance equation (1) and ordering policy (5), we can obtain

$$
\begin{aligned}
& O_{i}^{\infty}=D_{i}^{\infty}+\rho_{i}\left(I_{i}^{T}-I_{i}^{\infty}\right), \quad \forall i \in\{1,2\}, \\
& D_{i}^{\infty}=O_{i}^{\infty}+\varphi_{L}\left(I_{j}^{\infty}-I_{i}^{\infty}\right), \quad j \neq i \in\{1,2\} .
\end{aligned}
$$

Combining (14) and (15), we can further obtain

$$
I_{i}^{\infty}=I_{i}^{T}+\frac{\varphi_{L} \rho_{j}\left(I_{j}^{T}-I_{i}^{T}\right)}{\varphi_{L}\left(\rho_{1}+\rho_{2}\right)+\rho_{1} \rho_{2}}, \quad j \neq i \in\{1,2\} .
$$

From above, we see that the steady state of the inventory is determined by the inventory target and by the difference between the inventory targets of the two retailers. In practice, a retailer who is faced with high demand may set a high inventory target. Under the lateral transshipment program, such a retailer tends to transfer his or her inventory to another retailer who sets a relatively low inventory target. To prevent stock-outs, the setting of the inventory target should satisfy $I_{i}^{\infty}-D_{i}^{\infty}>0$.

In the following, we will consider the second scenario $\xi=$ $\xi_{2}$, in which only retailer 1 places orders with the upstream supplier. Similarly, we can obtain

$$
\begin{aligned}
& I_{1}^{\infty}=\frac{\varphi_{L} \mathrm{SI}^{T}+D_{2}^{\infty}}{2 \varphi_{L}}, \\
& I_{2}^{\infty}=\frac{\varphi_{L} \mathrm{SI}^{T}-D_{2}^{\infty}}{2 \varphi_{L}} .
\end{aligned}
$$

In scenario $\xi_{2}$, retailer 1 will frequently transfer his or her inventory to retailer 2 . It is very interesting to observe that the steady states of both retailers' inventories are independent of $D_{1}^{\infty}$, because the demands of retailer 2 are fully satisfied by lateral transshipments. Consequently, retailer 1 may become the leader due to the authorized right to control inventory for both retailers. To sustain customers' satisfaction, the parameter setting should satisfy $I_{i}^{\infty}-D_{i}^{\infty}>$ 0 , which leads to the following condition for parameters selection:

$$
2 D_{1}^{\infty}-\mathrm{SI}^{T} \leq \frac{D_{2}^{\infty}}{\varphi_{L}} \leq \mathrm{SI}^{T}-2 D_{2}^{\infty},
$$

which implicitly satisfies $\mathrm{SI}^{T}>D_{1}^{\infty}+D_{2}^{\infty}$. It means that increasing the target of system inventory enlarges the space of the selection of $\varphi_{L}$. We shall now consider the cases $D_{1}^{\infty}=200$ and $D_{2}^{\infty}=100$. If we set $\mathrm{SI}^{T}=320$, we should satisfy $\varphi_{L}>0.8$; otherwise, if we set $\mathrm{SI}^{T}=1000$, then $\varphi_{L}>0.125$ guarantees the desired service level. Recall that $0<\varphi_{L}<1$; thus setting a relative high value for $\varphi_{L}$ is significant for achieving high customer service level. However, a high $\varphi_{L}$ may bring stability problem, which will be investigated in Section 3.2. In principle, the decision-making for the selection of parameters should take into account the trade-off between the inventory cost and customers' satisfaction.

3.2. Stability Analysis. According to the scenarios aforementioned, the supply chain system can be analyzed under 5 different cases.

Case $1\left(\xi=\xi_{1}\right.$ and $\left.\varphi_{L}=0\right)$. There exist no lateral transshipments and the two retailers make replenishment decisions independently. This case is selected for comparison and highlights the dynamic complexities brought by lateral transshipments.

Case $2\left(\xi=\xi_{1}, \varphi_{L} \neq 0\right.$, and $\left.\tau=0\right)$. The retailers also make independent inventory decisions, and the lateral transshipments are incorporated. Note that the lead time of lateral transshipments is neglected as in [33] $(\tau=0)$. 
Case $3\left(\xi=\xi_{1}, \varphi_{L} \neq 0\right.$, and $\left.\tau \neq 0\right)$. The retailers also make independent inventory decisions and the lateral transshipments are incorporated. However, we consider the impact of the lead time in lateral transshipments on the stability problem $(\tau \neq 0)$.

Case $4\left(\xi=\xi_{2}, \varphi_{L} \neq 0\right.$, and $\left.\tau=0\right)$. In this case, we focus on scenario $\xi_{2}$. To simplify the analysis, we firstly neglect the impact of the transshipment lead time.

Case $5\left(\xi=\xi_{2}, \varphi_{L} \neq 0\right.$, and $\left.\tau \neq 0\right)$. In this case, we focus on scenario $\xi_{2}$. In contrast to Case 4 , we consider a nonnegligible transshipment lead time.

It is noteworthy that we consider 3 cases for $\xi=\xi_{1}$ and 2 cases for $\xi=\xi_{2}$. This is because the demand of retailer 2 cannot be satisfied without lateral transshipments.

In the following, we will perform detailed stability analysis for the above 5 cases.

Case 1. Let $\varphi_{L}=0, \xi=\xi_{1}$, and the eigenvalues for the state space model are computed as $\lambda_{1}=1-\theta_{1}, \lambda_{2}=$ $1-\theta_{2}, \lambda_{3}=1-\rho_{1}$, and $\lambda_{4}=1-\rho_{4}$. According to the Schur Theorem [39], the system will be stable as long as $0<\theta_{i}<1,0<\rho_{i}<2$, where $i=1 ; 2$. This condition is consistent with the results derived in [31]. It is noteworthy that $0<\theta_{i}<1$ is the trivial condition for generating stable forecasting results in the exponential algorithm. As a result, the stability of the supply chain system in this case with no lateral transshipments is determined only by replenishment parameters.

Case 2. Let $\varphi_{L}=0, \xi=\xi_{1}$, and $\tau=0$. Applying the $z$ transform [39], we can obtain the characteristic equation of the state space model. By ignoring the impacts of $\theta_{i}, i=1,2$, we find that the stability of the dynamic system is determined by

$$
\left(\lambda-1+\rho_{1}+\varphi_{L}\right)\left(\lambda-1+\rho_{2}+\varphi_{L}\right)=\varphi_{L}^{2} .
$$

The two roots of (19) are

$$
\lambda_{1,2}=\frac{2-\rho_{1}-\rho_{2}-2 \varphi_{L} \pm \sqrt{\rho_{1}^{2}+\rho_{2}^{2}-2 \rho_{1} \rho_{2}+4 \varphi_{L}^{2}}}{2} .
$$

We can get a necessary and sufficient stability condition for $\varphi_{L} \neq 0$ and $\tau=0$ by making $\left|\lambda_{1,2}\right|<1$, which is given by Theorem 1 .

Theorem 1. Assume that $\tau=0$. For the scenario $\xi=\xi_{1}$, the sufficient and necessary stability condition for the supply chain system is $\rho_{1}+\rho_{2}<4$ and

$$
\varphi_{L}<\frac{\left(2-\rho_{1}\right)\left(2-\rho_{2}\right)}{4-\rho_{1}-\rho_{2}} .
$$

Proof. We firstly consider $\lambda_{1}$ in (20). The condition $\left|\lambda_{1}\right|<1$ is equivalent to

$$
\sqrt{\rho_{1}^{2}+\rho_{2}^{2}-2 \rho_{1} \rho_{2}+4 \varphi_{L}^{2}}<4-\rho_{1}-\rho_{2}-2 \varphi_{L},
$$

which can be written as

$$
\begin{aligned}
\rho_{1}+\rho_{2}+2 \varphi_{L} & <4, \\
4+\rho_{1} \rho_{2}+\varphi_{L}\left(\rho_{1}+\rho_{2}\right)-2 \rho_{1}-2 \rho_{2}-4 \varphi_{L} & >0 .
\end{aligned}
$$

It must satisfy $\rho_{1}+\rho_{2}<4$ and

$$
\begin{aligned}
\varphi_{L} & <\min \left\{\frac{4-\rho_{1}-\rho_{2}}{2}, \frac{\left(2-\rho_{1}\right)\left(2-\rho_{2}\right)}{4-\rho_{1}-\rho_{2}}\right\} \\
& =\frac{\left(2-\rho_{1}\right)\left(2-\rho_{2}\right)}{4-\rho_{1}-\rho_{2}} .
\end{aligned}
$$

Now, we focus on $\lambda_{2}$. The condition $\left|\lambda_{2}\right|<1$ is equivalent to

$$
\begin{aligned}
& \sqrt{\rho_{1}^{2}+\rho_{2}^{2}-2 \rho_{1} \rho_{2}+4 \varphi_{L}^{2}}<\rho_{1}+\rho_{2}+2 \varphi_{L}, \\
& 4-\rho_{1}-\rho_{2}-2 \varphi_{L}+\sqrt{\rho_{1}^{2}+\rho_{2}^{2}-2 \rho_{1} \rho_{2}+4 \varphi_{L}^{2}}>0 .
\end{aligned}
$$

According to the above analysis, when $\left|\lambda_{1}\right|<1$, we must have $\rho_{1}+\rho_{2}+2 \varphi_{L}<4$. Thus, $\left|\lambda_{2}\right|<1$ can be satisfied if

$$
\sqrt{\rho_{1}^{2}+\rho_{2}^{2}-2 \rho_{1} \rho_{2}+4 \varphi_{L}^{2}}<\rho_{1}+\rho_{2}+2 \varphi_{L}
$$

The above condition holds because $\rho_{1} \rho_{2}+\rho_{1} \varphi_{L}+\rho_{2} \varphi_{L}>0$, which completes the proof.

From Theorem 1, we can further obtain

$$
\lim _{\rho_{1} \rightarrow 2, \rho_{2} \rightarrow 2} \frac{\left(2-\rho_{1}\right)\left(2-\rho_{2}\right)}{4-\rho_{1}-\rho_{2}}=0,
$$

which implies that the lateral transshipments can easily destabilize the system. In this sense, we find that lateral transshipments further complicate the dynamics. In practice, managers should be cautious in selecting the parameters of lateral transshipments.

Case 3. Based on the analysis of Case 2, we will consider the case $\tau \neq 0$ to disclose the impact of the lead time in lateral transshipments. The stability condition for this case is represented by Theorem 2 .

Theorem 2. Assume that $\tau \neq 0$. For the scenario $\xi=\xi_{1}$, the supply chain system is always stable if

$$
\left(1+\varphi_{L}\right)\left|\rho_{1}+\rho_{2}-2\right|+\left|\left(\rho_{1}-1\right)\left(\rho_{2}-1\right)\right|+2 \varphi_{L}<1,
$$

while it is unstable if

$$
\varphi_{L}>\frac{1}{\left|\rho_{1}+\rho_{2}-2\right|} .
$$

Proof. Using $z$ transform [39], the characteristic equation of the state space model is obtained as

$$
\begin{aligned}
z^{\tau+2}+ & \left(\rho_{1}+\rho_{2}-2\right) z^{\tau+1}+\left(\rho_{1} \rho_{2}-\rho_{1}-\rho_{2}+1\right) z^{\tau} \\
& +2 z \varphi_{L}+\left(\rho_{1}+\rho_{2}\right) \varphi_{L}-2 \varphi_{L}=0 .
\end{aligned}
$$




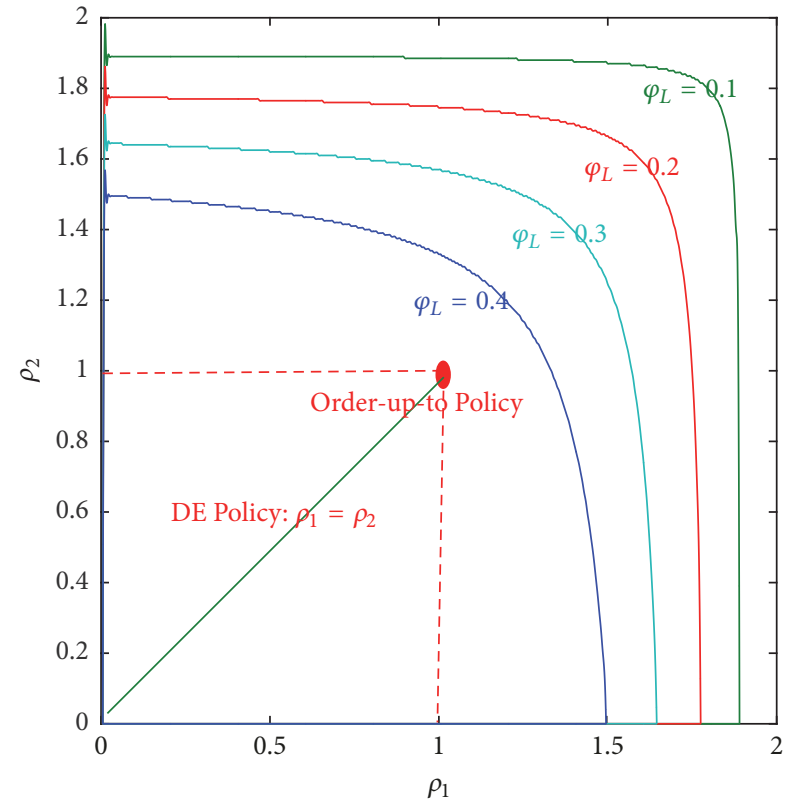

(a) Exact stable boundaries when $\tau=0$

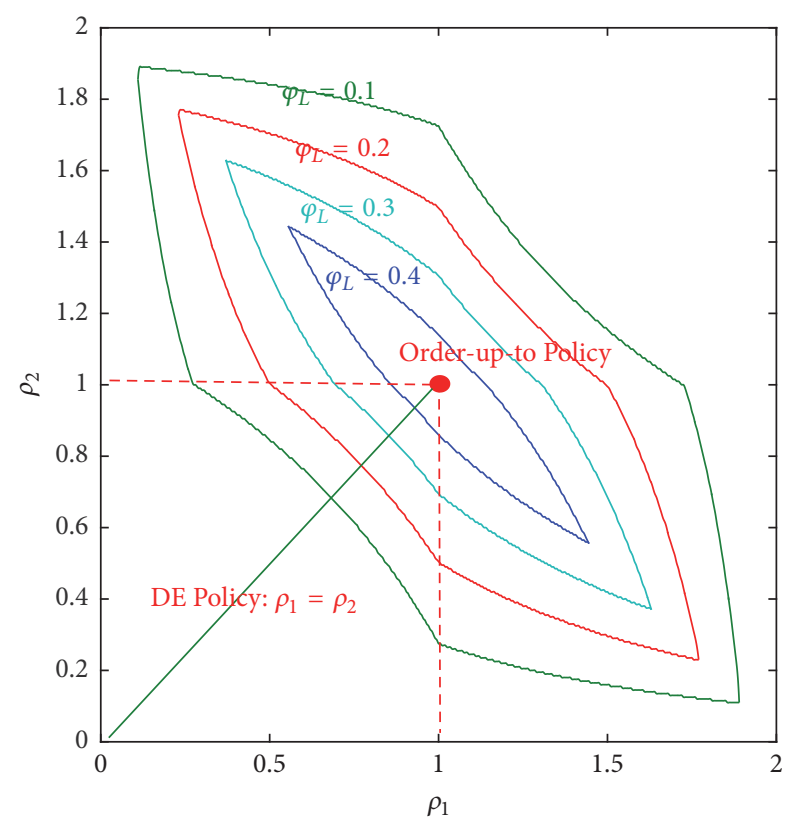

(b) Stable boundaries independent of $\tau$

FIgURE 2: Stable boundaries in scenario $\xi_{1}$.

It is infeasible to derive closed-form solutions for the above equation, because it is a transcendental equation and the number of roots depends on the value of $\tau$. However, we know that there exist $\tau+2$ roots, which are denoted by $\lambda_{1}, \lambda_{2}, \ldots, \lambda_{\tau+2}$. Then, the characteristic polynomial can be expressed as

$$
\begin{aligned}
p(z)= & \prod_{i=1}^{\tau+2}\left(z-\lambda_{i}\right) \\
= & z^{\tau+2}+\left(\rho_{1}+\rho_{2}-2\right) z^{\tau+1} \\
& +\left(\rho_{1} \rho_{2}-\rho_{1}-\rho_{2}+1\right) z^{\tau}+2 z \varphi_{L} \\
& +\left(\rho_{1}+\rho_{2}\right) \varphi_{L}-2 \varphi_{L} .
\end{aligned}
$$

A sufficient stability condition is obtained as $|p(0)|=$ $\prod_{i=1}^{\tau+2}\left|\lambda_{i}\right|<1$. Otherwise, there exists at least one root outside the unit circle. Thus, if $\left|\left(\rho_{1}+\rho_{2}\right) \varphi_{L}-2 \varphi_{L}\right|>1$, the system must be unstable. This completes the proof for (28).

Using Rouches' Theorem [40], we can decompose the characteristic polynomial as $p(z)=p_{1}(z)+p_{2}(z)$ with $p_{1}(z)=$ $z^{\tau+2}$ and

$$
\begin{aligned}
p_{2}(z)= & \left(\rho_{1}+\rho_{2}-2\right) z^{\tau+1}+\left(\rho_{1} \rho_{2}-\rho_{1}-\rho_{2}+1\right) z^{\tau} \\
& +2 z \varphi_{L}+\left(\rho_{1}+\rho_{2}\right) \varphi_{L}-2 \varphi_{L} .
\end{aligned}
$$

For $|z|=1$, if we have $\left|p_{2}(z)\right|<\left|p_{1}(z)\right|$, the number of roots inside the unit circle for both $p_{1}(z)=0$ and $p(z)=0$ will be equal. Because all the roots of $p_{1}(z)=0$ are inside the unit circle, we can have

$$
\begin{aligned}
& \left|p_{2}(z)\right|_{|z|=1}=\mid\left(\rho_{1}+\rho_{2}-2\right) z^{\tau+1} \\
& \quad+\left(\rho_{1} \rho_{2}-\rho_{1}-\rho_{2}+1\right) z^{\tau}+2 z \varphi_{L}+\left(\rho_{1}+\rho_{2}\right) \varphi_{L}
\end{aligned}
$$

$$
\begin{aligned}
& -\left.2 \varphi_{L}\right|_{|z|=1} \leq\left|\rho_{1}+\rho_{2}-2\right|+\left|\rho_{1} \rho_{2}-\rho_{1}-\rho_{2}+1\right| \\
& +\left|\left(\rho_{1}+\rho_{2}-2\right) \varphi_{L}\right|+2 \varphi_{L} .
\end{aligned}
$$

Finally, as long as $\left|\rho_{1}+\rho_{2}-2\right|\left(1+\varphi_{L}\right)+\left|\left(\rho_{1}-1\right)\left(\rho_{2}-1\right)\right|+$ $2 \varphi_{L}<1$, the state space model will be stable for arbitrary $\tau$. This completes the proof for Theorem 2 .

The stability conditions in Theorems 1 and 2 are illustrated in Figure 2. Figure 2(a) shows the precise stable regions for the different parameters in lateral transshipment with $\tau=0$. It is apparent that increasing the parameter $\varphi_{L}$ can fall outside unstable regions. As mentioned, the inventory policy (5) is a generalized order-up-to policy; in particular, when $\rho_{1}=\rho_{2}=$ 1 , the replenishment policy becomes an adaptive order-upto policy. For such a policy, we know that the supply chain system will be stable if and only if $\varphi_{L}<0.5$ from Theorem 1 . This condition can be easily satisfied because $\varphi_{L}>0.5$ reflects the situations with swapped inventory, which might cause unnecessary lateral transshipment costs. As found in [27], the DE Policy $\rho_{1}=\rho_{2}$ stabilizes a single-echelon inventory control system. However, the stability condition becomes $\varphi_{L}<1-0.5 \rho_{1}$ with lateral transshipments. This result differs from those in [31], implying that the lateral transshipments lead to the destabilization of supply chain systems.

Figure 2(b) illustrates the stable regions independent of $\tau$ for different $\varphi_{L}$. Theorem 2 provides stable regions for arbitrary lateral transshipment lead time, which simplifies the selection of replenishment parameters, because it is difficult to obtain the precise stable region for each $\tau$. It again demonstrates that increasing $\varphi_{L}$ further complicates the stability problem. For a special case $\rho_{1}=\rho_{2}=1$, we can obtain 
that $\varphi_{L}<0.5$ ensures the stability for the whole dynamic system.

Case 4. In the following, we focus on the second scenario $\xi_{2}$. In this scenario, it is impossible for the second retailer to satisfy demand if $\varphi_{L}=0$. Thus, we firstly consider a simple case $\tau=0$ and $\varphi_{L} \neq 0$, for which the stability condition is given by Theorem 3 .

Theorem 3. When $\tau=0$ and $\varphi_{L} \neq 0$, for the scenario $\xi_{2}$, the supply chain system is stable if and only if $0<\rho<2$ and $0<\varphi_{L}<1$.

The proof for Theorem 3 can be completed by analyzing the two eigenvalues of the system:

$$
\lambda_{1,2}=\frac{2-\rho-2 \varphi_{L} \pm\left|\rho-2 \varphi_{L}\right|}{2} .
$$

Theorem 3 shows a trivial stability condition under which the demand of the two retailers can be satisfied even if only one retailer places orders with the upstream supplier.

Case 5. When $\tau \neq 0$, we can obtain the stability condition represented by Theorem 4 , which is introduced as follows.

Theorem 4. Under the scenario $\xi=\xi_{2}$, the supply chain system is stable if $0<\rho<2,0<\varphi_{L}<2$, and

$$
\tau<\frac{\pi-\arccos \left(1-2 \varphi_{L}^{2}\right)}{2 \arccos \left(1-2 \varphi_{L}^{2}\right)} .
$$

Proof. For the scenario $\xi=\xi_{2}$, the characteristic equation becomes

$$
(z-1+\rho)\left(z-1+2 \varphi_{L} z^{-\tau}\right)=0 .
$$

Thus, $0<\rho<2$ is a necessary condition to ensure system stability. The other conditions are contingent upon the roots of the following equation:

$$
z^{\tau+1}-z^{\tau}+2 \varphi_{L}=0 .
$$

Without loss of generality, substituting $z=\gamma e^{j \omega}$ into (37), we can further obtain $\left(\gamma e^{j \omega}\right)^{\tau+1}-\left(\gamma e^{j \omega}\right)^{\tau}+2 \varphi_{L}=0$. According to Euler's formula $e^{j \omega}=\cos (\omega)+j \sin (\omega)$, we can further obtain

$$
\begin{array}{r}
\gamma^{\tau+1} \cos [(\tau+1) \omega]-\gamma^{\tau} \cos (\tau \omega)+2 \varphi_{L}=0, \\
\gamma^{\tau+1} \sin [(\tau+1) \omega]-\gamma^{\tau} \sin (\tau \omega)=0 .
\end{array}
$$

When $\omega=0$, we must have $\gamma^{\tau+1}-\gamma^{\tau}+2 \varphi_{L}=0$ and further obtain $0<\gamma<1$. It implies that $\omega=0$ ensures the stability for the system. Combining (38) and (39), we can derive

$$
\begin{aligned}
\gamma^{2 \tau+2}+\gamma^{2 \tau}-2 \gamma^{2 \tau+1} \cos (\omega) & =4 \varphi_{L}^{2}, \\
\gamma \sin [(\tau+1) \omega] & =\sin (\tau \omega) .
\end{aligned}
$$

When $\gamma=1$, we have $\sin [(\tau+1) \omega]=\sin (\tau \omega)$. Because $(\tau+1) \omega-\tau \omega=\omega<2 \pi$, we can obtain $(\tau+1) \omega+\tau \omega=\pi$. Let $\omega^{*}=\pi /(2 \tau+1)$. We can know if $0<\omega<\pi /(2 \tau+1)$, we must satisfy $\gamma<1$. When $\gamma=1$, we can also have $1-2 \varphi_{L}^{2}=\cos (\omega)$. Further, we can have $\omega^{*}=\arccos (1-$ $\left.2 \varphi_{L}^{2}\right)=\pi /(2 \tau+1)$, which gives a critical value for $\tau: \tau^{*}=$ $\left(\pi-\arccos \left(1-2 \varphi_{L}^{2}\right)\right) / 2 \arccos \left(1-2 \varphi_{L}^{2}\right)$. This completes the proof of Theorem 4 .

Theorem 4 imposes a constraint on the lead time in lateral transshipments in ensuring the stability of the whole system for different $\varphi_{L}$. It is evident that the system becomes more unstable with increasing values of the parameter $\varphi_{L}$. We can also obtain

$$
\lim _{\varphi_{L} \rightarrow 0} \frac{\pi-\arccos \left(1-2 \varphi_{L}^{2}\right)}{2 \arccos \left(1-2 \varphi_{L}^{2}\right)}=\infty,
$$

which implies that, for a small $\varphi_{L}$, the lead time in lateral transshipments exerts only a negligible effect on system stability. When $\varphi_{L}=0.5$, the stability condition becomes $0<$ $\tau<1$. For a discrete system, $\tau$ is usually an integer. Thus, the supply chain system with $\varphi_{L}=0.5$ can be easily destabilized if we increase the lead time in lateral transshipments.

\section{Simulation Experiments}

4.1. Stability Validation. This section will validate the stability results. The customer demand of the two retailers is exogenous and thus exerts no effect on system stability. The step signal is selected to test the dynamics because of its wide use in studying the dynamics and system performance of supply chain systems. For example, the step signal has been used to model sudden changes in customer demand after price promotion activities [41]. In addition, the well-known Supply Chain Operations Reference (SCOR) model also measures supply chain performance in response to a step change in customer demand [25, 41]. The demands of retailer 1 before the 5 th period are 4 units; the demands after the 5 th period are 8 units. The demand amount of retailer 1 is assumed to be twice that of retailer 2 in any period. The initial values of retailers 1 and 2 are 4 and 8 units, respectively. We subjectively select the values for the specific amounts of demands and initial value of inventory because they exert no effect on system stability. Since the demand forecasting algorithm is not incorporated into any feedback loops, the parameters $\theta_{1}$ and $\theta_{2}$ do not affect system stability and therefore we set $\theta_{1}=\theta_{2}=0.2$.

We mainly validate Theorems 1,2 , and 4 . Case 1 is excluded from our simulation experiments due to its simplicity. For Theorems 1 and 2, we attempt to cover both stable and unstable dynamics, which lead to 6 simulation designs. For Theorem 4 corresponding to scenario $\xi_{2}$, except stable and unstable design, we also include a critically stable design. The parameters $\rho_{1}, \rho_{2}, \rho, \varphi_{L}$, and $\tau$ are selected on the basis of the theoretical results in Section 3. Finally, a total of 9 simulation designs are tested, which are shown in Table 1. According to the demand and lead time assumptions, we set the inventory targets for the two retailers as $I_{1}^{T}=8$ and $I_{2}^{T}=4$ 
TABLE 1: Simulation designs for stability validation.

\begin{tabular}{lccccccc}
\hline Simulation design & Scenario & $\rho_{1}$ & $\rho_{2}$ & $\rho$ & $\varphi_{L}$ & $\tau$ & Theorem \\
\hline Design 1 & $\xi_{1}$ & 1.5 & 1.5 & - & 0.2 & 0 & Theorem 1 \\
Design 2 & $\xi_{1}$ & 1.5 & 1.5 & - & 0.3 & 0 & Theorem 1 \\
Design 3 & $\xi_{1}$ & 0.8 & 1.2 & - & 0.2 & 2 & Theorem 2 \\
Design 4 & $\xi_{1}$ & 0.8 & 1.2 & - & 0.2 & 12 & Theorem 2 \\
Design 5 & $\xi_{1}$ & 0.8 & 0.6 & - & 0.4 & 2 & Theorem 2 \\
Design 6 & $\xi_{1}$ & 0.8 & 0.6 & - & 0.4 & Theorem 2 \\
Design 7 & $\xi_{2}$ & - & - & 0.6 & 0.12 & 5 & Theorem 4 \\
Design 8 & $\xi_{2}$ & - & - & 0.6 & 0.12 & 6 & Theorem 4 \\
Design 9 & $\xi_{2}$ & - & - & 0.6 & 0.12 & 7 & Theorem 4 \\
\hline
\end{tabular}

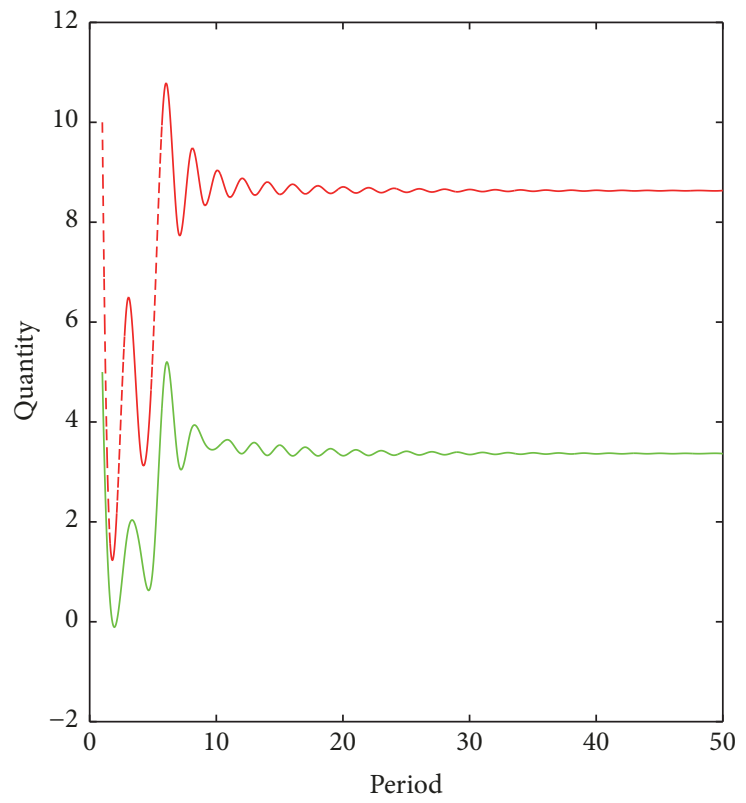

- - Order of retailer 1

- Order of retailer 2

(a) $\rho_{1}=1.5, \rho_{2}=1.5, \varphi_{L}=0.2$

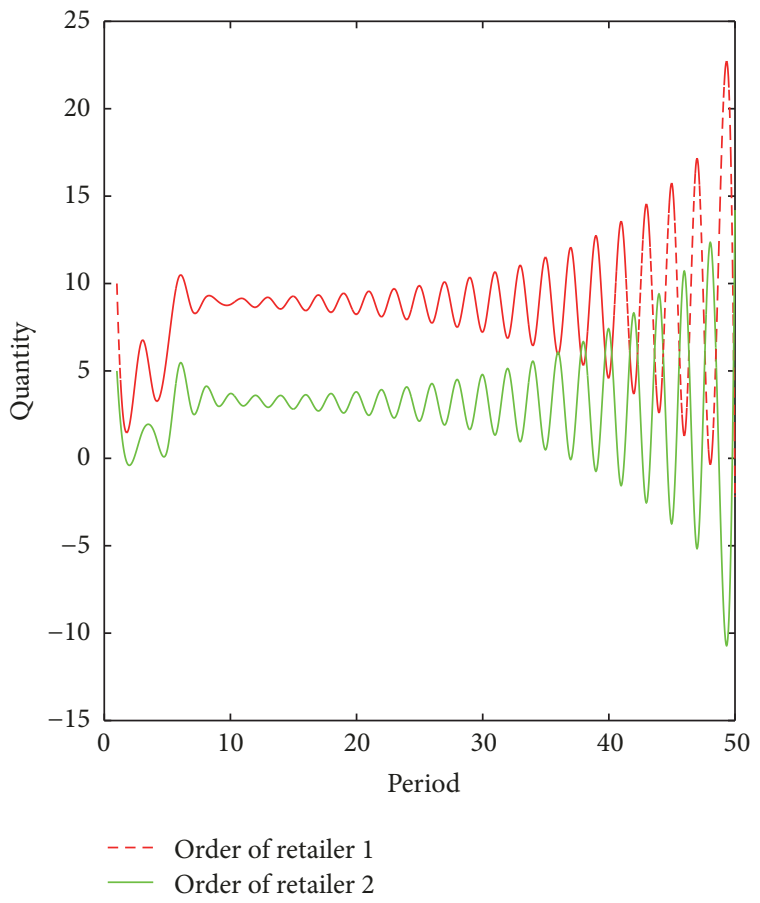

(b) $\rho_{1}=1.5, \rho_{2}=1.5, \varphi_{L}=0.3$

FIgURE 3: Stability validation for Theorem 1.

for scenario $\xi_{1}$ (designs 1-6). The inventory target for scenario $\xi_{2}$ (designs 7-9) is set as $\mathrm{SI}^{T}=12$.

(1) Validation for Scenario $\xi_{1}$. To test Case 2, we consider the parameter setting $\rho_{1}=\rho_{2}=1.5$. From Theorem 1, we see that $\varphi_{L} \leq 0.25$ guarantees system stability. Figure 3(a) shows the order dynamics for design 1 when $\rho_{L}=0.2$, while Figure 3(b) shows the order dynamics for design 2 when $\rho_{L}=0.3$. It shows that in design 1 the inventory and order return to steady states after some periods, whereas design 2 generates divergent behaviors. In reality, such divergent behaviors may be interrupted due to limited capacities with respect to storage space or funds. However, unstable systems frequently tend to accumulate inventory or lead to stock-outs. If timely interventions are not taken, high inventory costs may be incurred.

Theorem 2 provides both stable and unstable regions independent of the lead time in lateral transshipments. It deserves attention that the parameter $\varphi_{L}$ plays a key role in these stability conditions. To validate Theorem 2, we firstly fix $\varphi_{L}=0.2$. Figures 4(a) and 4(b) validate the stability condition (28) in Theorem 2 with design 3 and design 4 . The finding is that both designs 3 and 4 are stable even if the lead time in lateral transshipments is increased to 12 periods from 2 periods. To validate (29), Figure 4(c) shows that design 5 is stable even when the parameters are outside the stable region independent of $\tau$ for $\rho_{1}=0.8, \rho_{2}=0.6, \tau=2$, and $\varphi_{L}=0.2$. However, as shown in Figure 4(d), design 6 becomes unstable as the lead time $\tau$ increases to 12 periods.

(2) Validation for Scenario $\xi_{2}$. For the state space model $\xi=\xi_{2}$, we only validate Theorem 4 due to its significance. When $\rho=$ $0.6, \varphi_{L}=0.12$, we find that the condition $\tau<6.02$ leads to stable designs by Theorem 4 . Figure 5(a) shows the order and inventory dynamics for design 7 with $\tau=5$, Figure 5(b) shows periodical oscillations for design 8 with $\tau=6$, and Figure 5(c) 

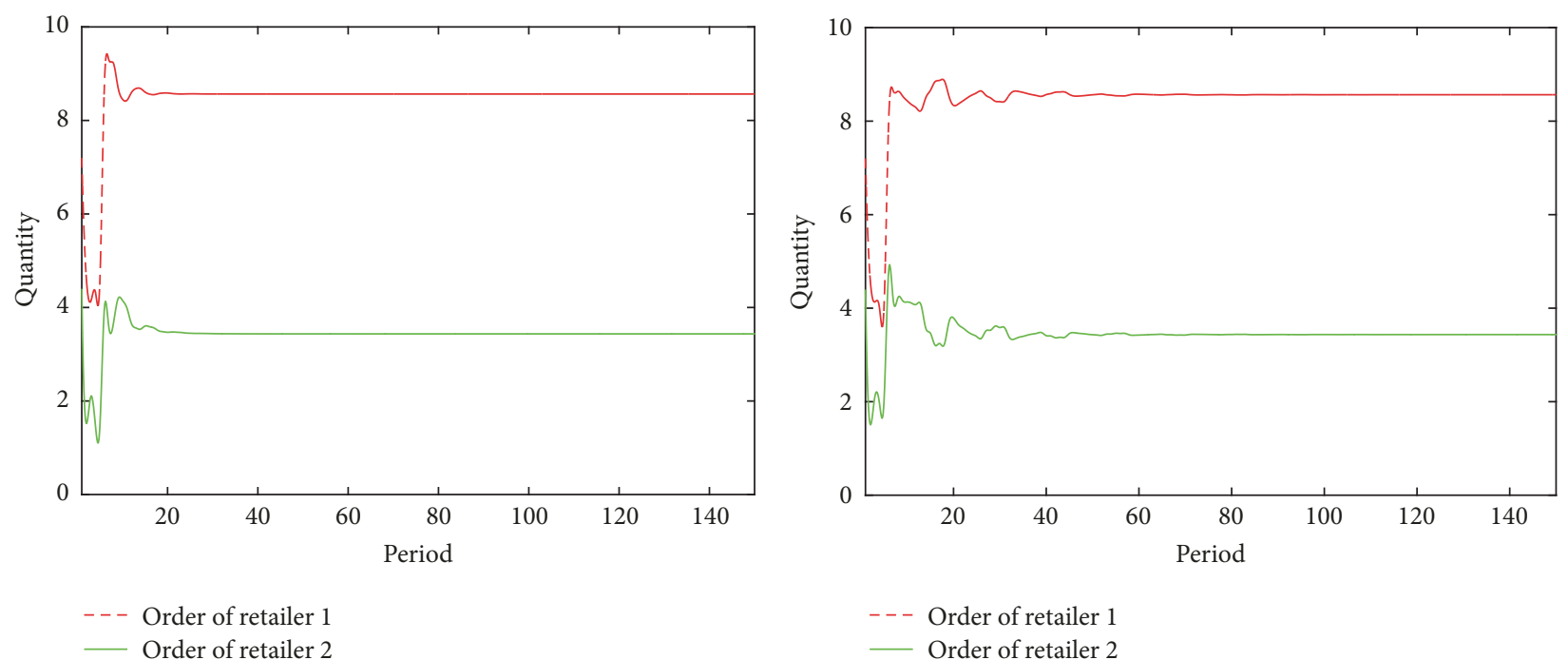

- - Order of retailer 1

Order of retailer 2

(a) $\rho_{1}=0.8, \rho_{2}=1.2, \varphi_{L}=0.2, \tau=2$

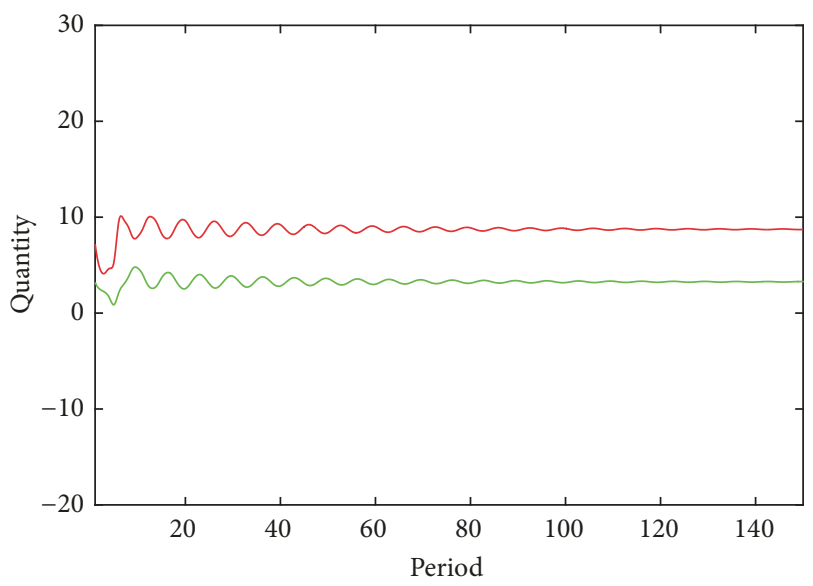

(b) $\rho_{1}=0.8, \rho_{2}=1.2, \varphi_{L}=0.2, \tau=12$

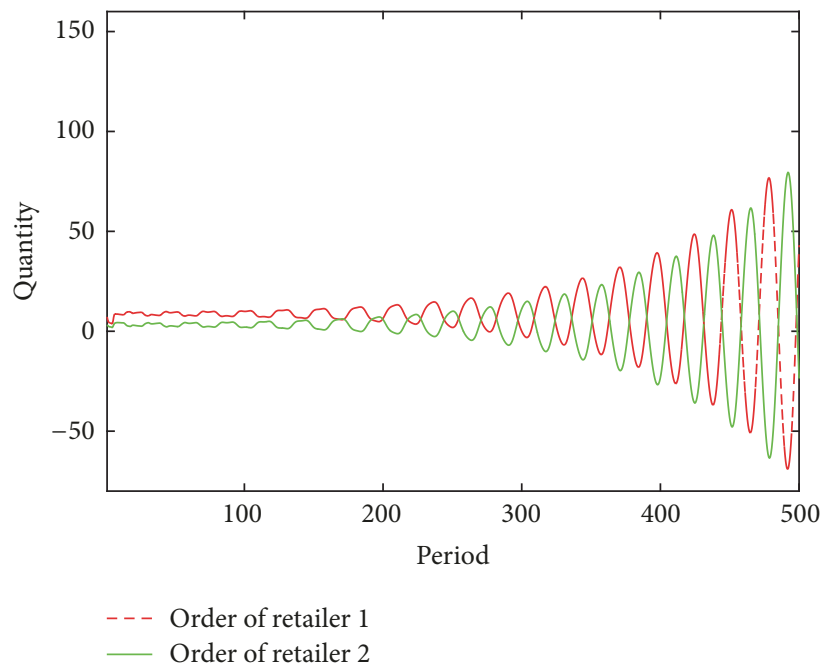

(d) $\rho_{1}=0.8, \rho_{2}=0.6, \varphi_{L}=0.4, \tau=12$

(c) $\rho_{1}=0.8, \rho_{2}=0.6, \varphi_{L}=0.4, \tau=2$

FIgURE 4: Stability validation for Theorem 2.

shows unstable dynamics for design 9 with $\tau=7$. Collectively, these results imply that increasing the lead time in lateral transshipments introduces great dynamic complexity into the system.

4.2. The Impact of Lateral Transshipment on System Performance. The question of stability is of fundamental significance for the selection of parameters. To further improve system performance, we will numerically disclose the impacts of parameters on the measurements introduced in Section 2.2 in both scenarios $\xi_{1}$ and $\xi_{2}$. Consider the following autoregressive demand model for the two retailers:

$$
\begin{aligned}
& D_{1}(t+1)=d_{1}+\mu_{1} D_{1}(t)+\left(1-\mu_{1}\right) \varepsilon_{1}(t)+\eta_{1} \varepsilon(t), \\
& D_{2}(t+1)=d_{2}+\mu_{2} D_{2}(t)+\left(1-\mu_{2}\right) \varepsilon_{2}(t)+\eta_{2} \varepsilon(t),
\end{aligned}
$$

where $\varepsilon_{1}(t) \sim \mathcal{N}\left(0, \sigma_{1}^{2}\right), \varepsilon_{2}(t) \sim \mathcal{N}\left(0, \sigma_{2}^{2}\right), \varepsilon(t) \sim \mathcal{N}\left(0, \sigma^{2}\right), d_{1}$ and $d_{2}$ are constant, $\mu_{1}$ and $\mu_{2}$ are autocorrelation coefficients, and $\eta_{1}$ and $\eta_{2}$ are cross-correlation coefficients satisfying $\eta_{1}, \eta_{2} \in\{-1,0,1\}$. When $\eta_{1}=\eta_{2}=1$, the demands of the two retailers are positively correlated; when $\eta_{1}=$ $\eta_{2}=0$, the demands of the two retailers are independent; when $\eta_{1}=-\eta_{2}=1$, the demands of the two retailers are negatively correlated. In the following simulation, in order to compute the measurements, we set the cost parameters as $c_{h}=0.2, c_{b}=0.4, c_{o}=0.2$, and $c_{l}=0.1$. We consider such a parameter setting because the marginal stock-out cost is usually higher than the marginal inventory holding cost. In addition, lateral transshipment occurs between nearby retailers while the replenishments from upstream suppliers usually incur high transportation cost.

(1) Scenario $\xi_{1}$. We consider a situation that two retailers whose market shares are quite close make independent replenishment decisions in scenario $\xi_{1}$. Then, we set the parameters in the demand model (43) as $d_{1}=d_{2}=100$, 


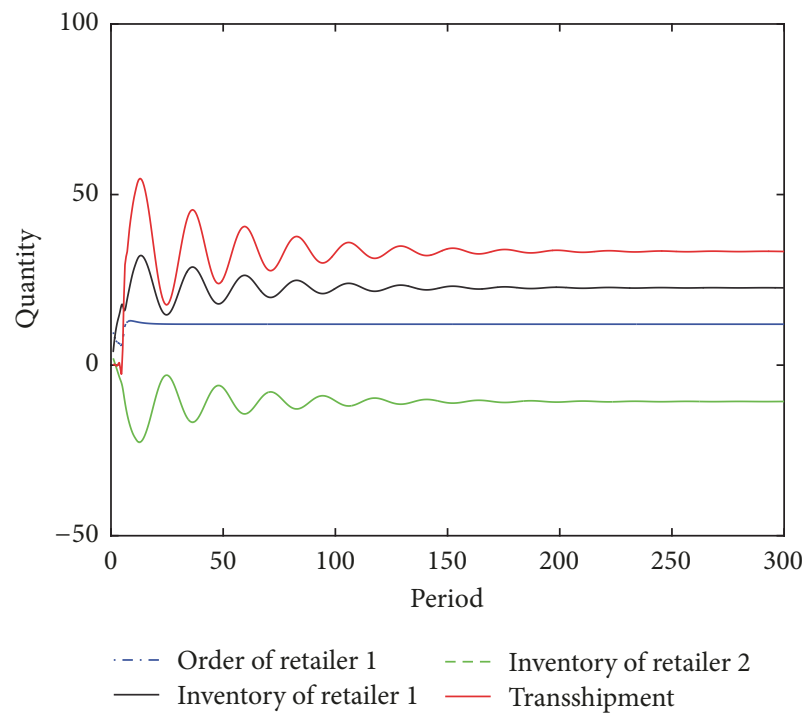

(a) $\rho=0.6, \varphi_{L}=0.12, \tau=5$

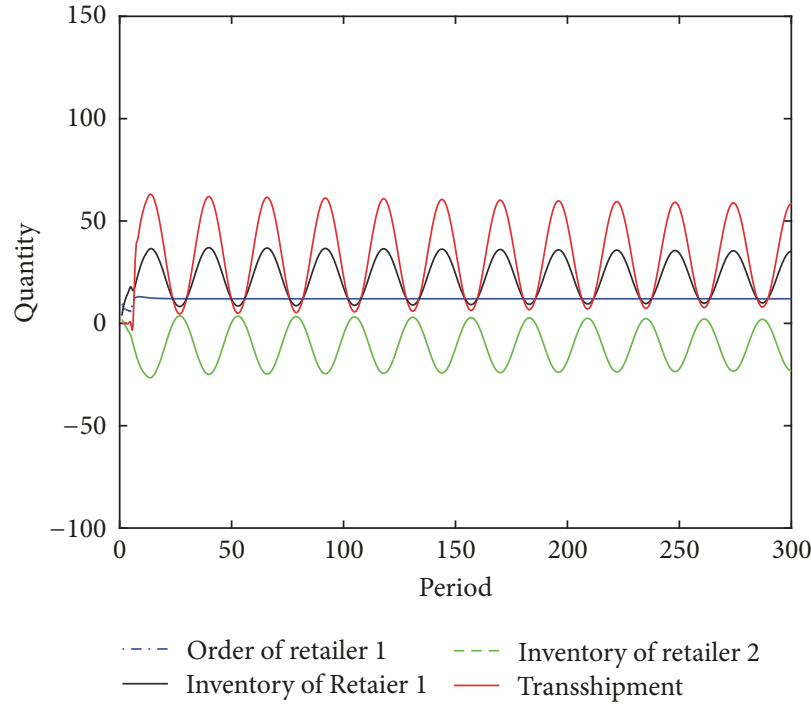

(b) $\rho=0.6, \varphi_{L}=0.12, \tau=6$

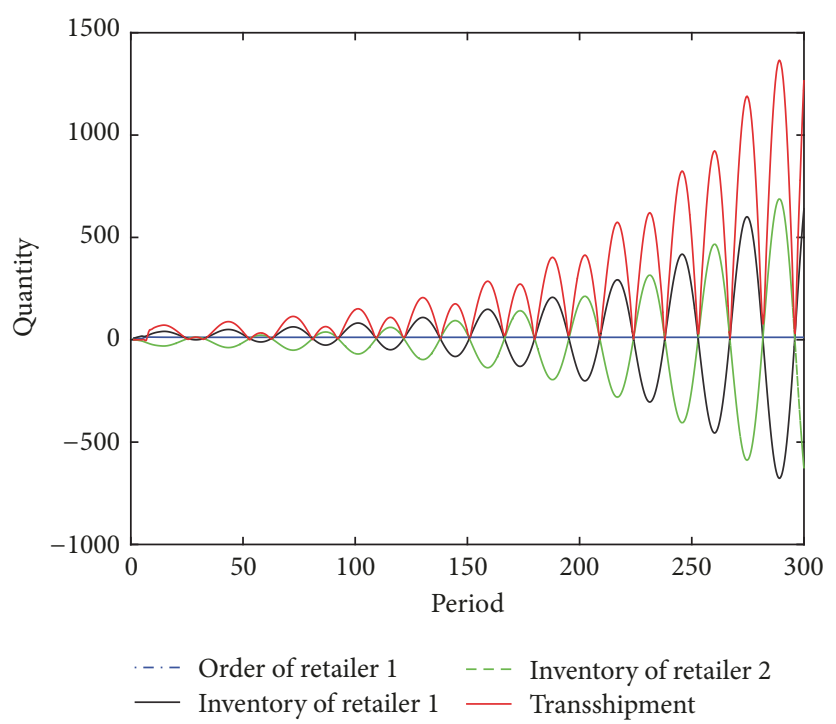

(c) $\rho=0.6, \varphi_{L}=0.12, \tau=7$

FIgURE 5: Stability validation for Theorem 4.

$\mu_{1}=\mu_{2}=0.4$, and $\sigma_{1}=\sigma_{2}=\sigma=10$. To simplify the analysis, the lead time of lateral transshipment is neglected with $\tau=0$. The inventory targets for the two retailers are set as $I_{1}^{T}=I_{2}^{T}=200$. The coefficients in the exponential smoothing algorithms are set as $\theta_{1}=\theta_{2}=0.2$. Because we focus on the impacts on lateral transshipments, we also fix the replenishment parameters falling into stable regions: $\rho_{1}=0.6$ and $\rho_{2}=0.8$. A total of 18 parameter settings are designed by varying the parameters $\eta_{1}, \eta_{2}$, and $\varphi_{L}$. The simulation length for each parameter setting is 50000 to avoid the impact of randomness.

The computational results for our performance measurements are shown in Table 2 and Figure 6 shows the trend of different performance measurements by varying the parameter $\varphi_{L}$, from which we can draw the following significant managerial insights. Firstly, increasing the amount of lateral transshipments improves the customer service level. This advantageous effect secondary to the pooling of the retailers' inventory is more obvious when the demands of the two retailers are negatively correlated. Secondly, increasing the parameter $\varphi_{L}$ incurs high lateral transshipment cost, especially for the case $\eta_{1}=-\eta_{2}=1$. This is caused by the corresponding rise in the quantity of lateral transshipments. In practice, managers should pay attention to the lateral transshipment costs especially when the distance between two retailers is very large. Thirdly, lateral transshipments are useful in mitigating the bullwhip effect when the parameter $\varphi_{L}$ assumes a moderate value, because a large $\varphi_{L}$ may lead to serious bullwhip effect problem. The bullwhip effect may be characterized as a convex function. In particular, this effect is evident for negatively correlated demands between the two retailers, as demonstrated in Figure 6(b). 
TABLE 2: The computational results of performance measurements in scenario $\xi_{1}$.

\begin{tabular}{|c|c|c|c|c|c|c|c|c|}
\hline$\eta_{1}$ & $\eta_{2}$ & $\varphi_{L}$ & TIC & TOC & LC & $\mathrm{SL}_{1}$ & $\mathrm{SL}_{2}$ & BW \\
\hline 0 & 0 & 0 & 13.41 & 66.67 & 0 & 0.99 & 0.99 & 1.05 \\
\hline 0 & 0 & 0.05 & 13.32 & 66.69 & 0.04 & 0.99 & 0.99 & 1.00 \\
\hline 0 & 0 & 0.15 & 13.32 & 66.69 & 0.11 & 0.99 & 0.99 & 0.94 \\
\hline 0 & 0 & 0.25 & 13.32 & 66.69 & 0.18 & 0.99 & 0.99 & 0.91 \\
\hline 0 & 0 & 0.35 & 13.32 & 66.69 & 0.25 & 0.99 & 0.99 & 0.90 \\
\hline 0 & 0 & 0.45 & 13.32 & 66.69 & 0.35 & 0.99 & 0.99 & 0.94 \\
\hline 1 & 1 & 0 & 14.13 & 66.67 & 0 & 0.93 & 0.94 & 1.05 \\
\hline 1 & 1 & 0.05 & 14.13 & 66.65 & 0.04 & 0.93 & 0.94 & 1.04 \\
\hline 1 & 1 & 0.15 & 14.12 & 66.65 & 0.11 & 0.93 & 0.94 & 1.02 \\
\hline 1 & 1 & 0.25 & 14.11 & 66.65 & 0.18 & 0.93 & 0.94 & 1.01 \\
\hline 1 & 1 & 0.35 & 14.10 & 66.65 & 0.26 & 0.93 & 0.94 & 1.01 \\
\hline 1 & 1 & 0.45 & 14.11 & 66.65 & 0.36 & 0.93 & 0.94 & 1.02 \\
\hline 1 & -1 & 0 & 14.09 & 66.68 & 0 & 0.93 & 0.94 & 1.05 \\
\hline 1 & -1 & 0.05 & 14.034 & 66.67 & 0.10 & 0.93 & 0.94 & 0.97 \\
\hline 1 & -1 & 0.15 & 13.94 & 66.67 & 0.28 & 0.94 & 0.95 & 0.87 \\
\hline 1 & -1 & 0.25 & 13.89 & 66.67 & 0.45 & 0.94 & 0.95 & 0.81 \\
\hline 1 & -1 & 0.35 & 13.88 & 66.67 & 0.64 & 0.95 & 0.95 & 0.80 \\
\hline 1 & -1 & 0.45 & 13.93 & 66.67 & 0.88 & 0.94 & 0.94 & 0.86 \\
\hline
\end{tabular}

(2) Scenario $\xi_{2}$. As mentioned, scenario $\xi_{2}$ fits the case that retailer 1 plays a dominant role in selling a certain type of product and places orders with the external supplier, while retailer 2 attempts to sell this product just by lateral transshipments as introduced in Section 2.1. In the following simulation, we consider two retailers with different market shares; for example, the demand amount of retailer is more than retailer 2 . Therefore, we set the parameters in the demand model as $d_{1}=100, d_{2}=20, \mu_{1}=\mu_{2}=0.4$, $\sigma_{1}=10, \sigma_{2}=2$, and $\sigma=10$. Similar to scenario $\xi_{1}$, we fix the demand smoothing coefficients and the replenishment parameter by $\theta_{1}=\theta_{2}=0.2$ and $\rho=0.6$. The lead time of lateral transshipments is also 0 . The systematic inventory target is set as $\mathrm{SI}^{T}=300$. The simulation length for each parameter setting is 50000 . By varying the parameters $\eta_{1}, \eta_{2}$, and $\varphi_{L}$, we can also obtain 15 simulation designs.

Table 3 shows the computational results for our performance measurements. The results differ from those in scenario $\xi_{1}$. We observe that the increase of lateral transshipments improves the customer service level for retailer 2 but can lead to stock-outs for retailer 1 . However, the shifting of the inventory reduces the total inventory cost for some specific values of $\varphi_{L}$. It is interesting that the lateral transshipment cost remains unchanged, since the fulfillment of the demand of retailer 2 is fully contingent upon retailer 1 . Another interesting observation is that the bullwhip effect can be amplified for positively correlated demand but mitigated for negatively correlated demand.

\section{Conclusions}

This paper aims to explore the dynamic complexities of a supply chain system with lateral transshipments. The horizontal transshipments between two retailers, coupled with the replenishment policies and lead time, render the structure of the whole system. These inventory rules culminate in multiple feedback loops and lead to dynamic complexities in terms of stability and system performance. To understand the complexities in such a system, we developed a unified state space model to incorporate two different scenarios. Based on the state space model, we analyzed the steady state of the supply chain system and analytical stability conditions are derived. The stability results demonstrate that lateral transshipments complicate the system dynamics more than do the traditional supply chain systems. Exactly, increasing the magnitude of lateral transshipments easily destabilizes a supply chain system, especially in the case with a long lead time of lateral transshipments. In the second scenario, we discerned the interesting observation that the demand of the two retailers can be satisfied even though only one retailer places orders with the upstream supplier.

Through simulation experiments, we have validated our theoretical results using a step signal demand. Based on the stability results, we selected different settings of parameter to disclose the advantages of lateral transshipments. The simulation results reveal that, in a decentralized supply chain, lateral transshipments improve customer service level in the scenario where each of the two retailers places orders with the upstream supplier. Improving customer service level is one of the main motivations for lateral transshipments, which has been validated widely in the existing literature $[3,42]$. We also find that negatively correlated demand reduces inventory cost, which supports the empirical results for merging firms [43]. In the scenario where only one retailer places orders, lateral transshipments jeopardize this retailer. However, we also notice that moderated lateral transshipments reduce inventory cost for the whole system.

Our periodic model is very general by incorporating 5 different cases in two scenarios without imposing any specific 


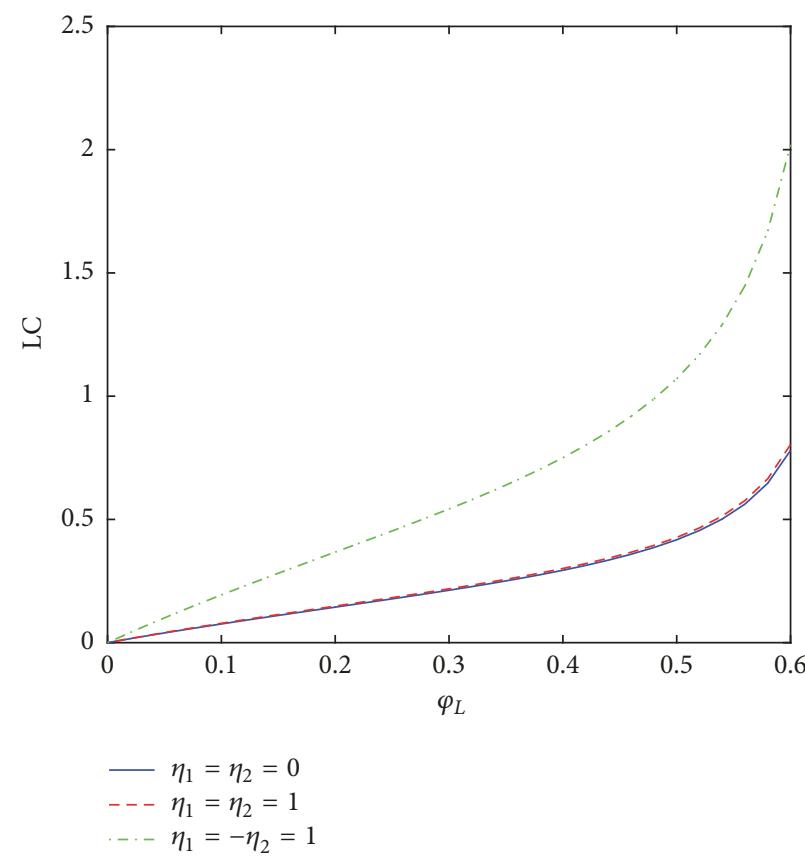

(a)

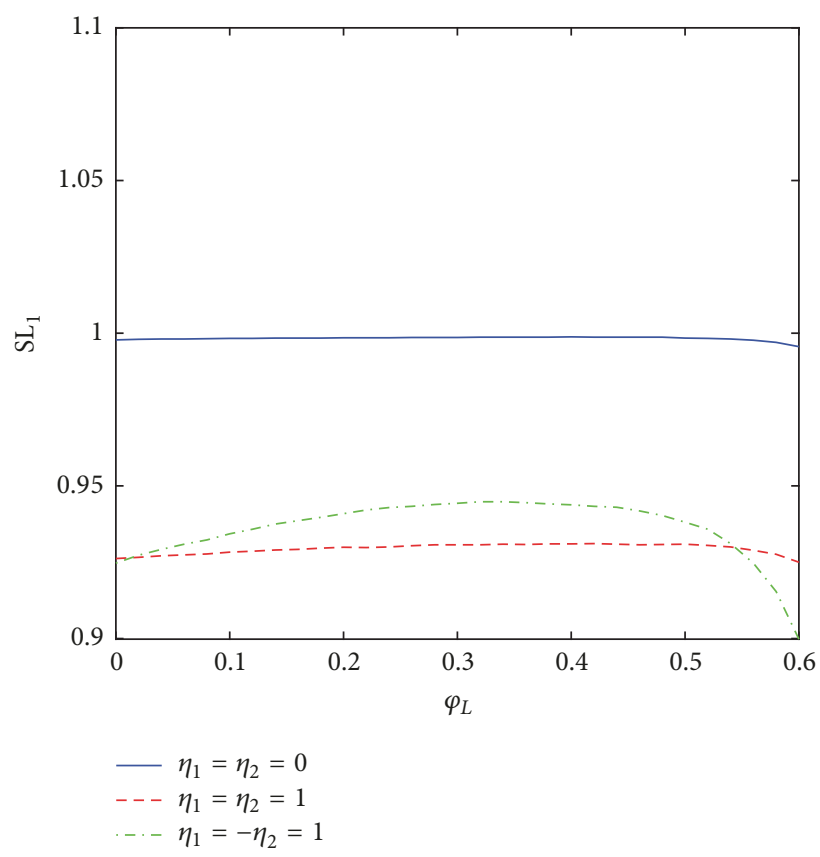

(c)

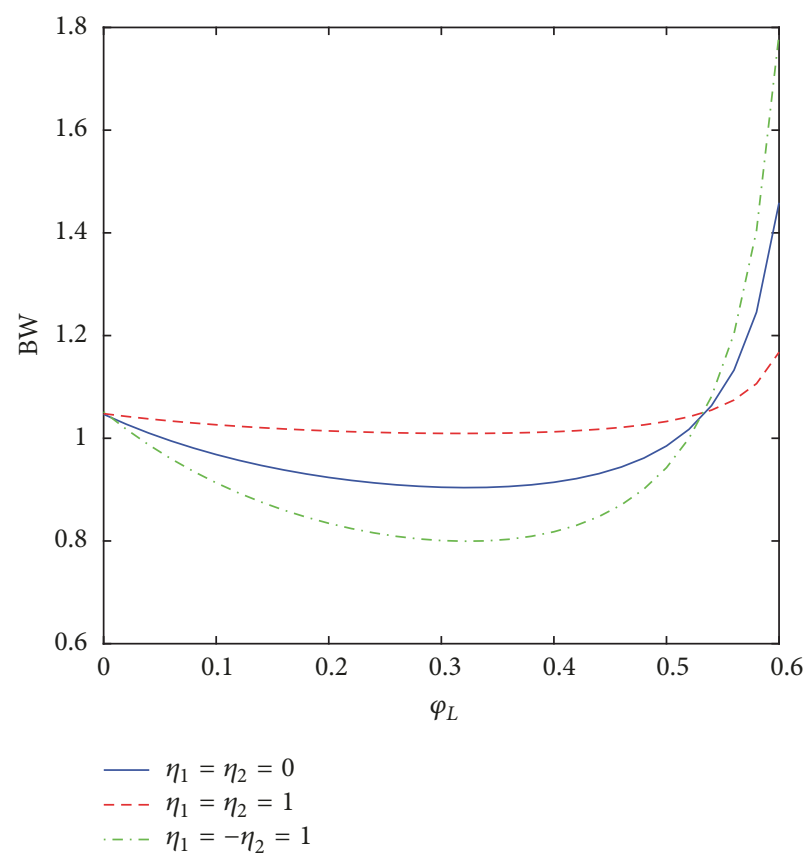

(b)

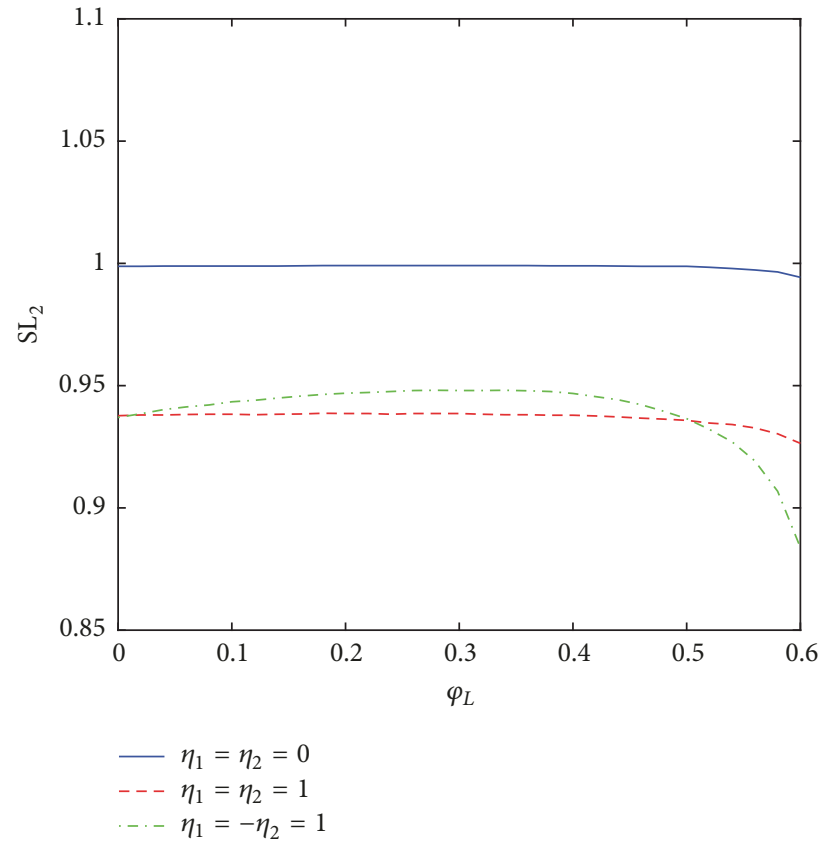

(d)

FIGURE 6: The impact of $\varphi_{L}$ on performance measurements under scenario $\xi=\xi_{1}$.

assumptions in demand. The results obtained are applicable to different industries, such as electrical and PC industries. In particular, we observe that the second scenario $\xi_{2}$ is also suitable for spare parts network, for example, the outlets networks supplying car parts in [7], in which retailers have very limited space to stock inventory due to high rents. Moreover, their demands for items are likely nonstationary as well as stochastic. In such situations, the second scenario of lateral transshipments $\xi_{2}$ better fits practical situations and will be helpful in reducing the inventory cost and mitigating the risks of shortfall.

This research can be extended from several aspects. One interesting problem is that replenishment lead times can be included in our model, which will further complicate the dynamics. Another interesting subject is the dynamic complexities of a supply chain network with multiple retailers and multiple suppliers and sees how demand uncertainty propagates along a network system. 
TABLE 3: The results on system performance in scenario $\xi_{2}$.

\begin{tabular}{ccccccccc}
\hline$\eta_{1}$ & $\eta_{2}$ & $\varphi_{L}$ & TIC & TOC & LC & SL $_{1}$ & SL $_{2}$ \\
\hline 0 & 0 & 0.05 & 150.01 & 40 & 3.33 & 1 & 0 \\
0 & 0 & 0.15 & 20.08 & 40 & 3.33 & 1 & 0.92 \\
0 & 0 & 0.25 & 19.99 & 40 & 3.33 & 1 & 0.94 \\
0 & 0 & 0.35 & 20 & 40 & 3.33 & 0.99 & 1 \\
0 & 0 & 0.45 & 20.07 & 40 & 3.33 & 0.97 & 1 & 1 \\
1 & 1 & 0.05 & 150.08 & 40.01 & 3.33 & 1 & 0.94 \\
1 & 1 & 0.15 & 25.75 & 40.01 & 3.33 & 0.99 & 0.94 \\
1 & 1 & 0.25 & 20.39 & 40.01 & 3.33 & 0.98 & 0.58 & 0.96 \\
1 & 1 & 0.35 & 20.60 & 40.01 & 3.33 & 0.91 & 1.73 \\
1 & 1 & 0.45 & 21.25 & 40.01 & 3.33 & 0.82 & 0.99 \\
1 & -1 & 0.05 & 150.31 & 39.99 & 3.34 & 1 & 0.99 \\
1 & -1 & 0.15 & 24.81 & 39.99 & 3.34 & 0.99 & 0 \\
1 & -1 & 0.25 & 20.17 & 39.99 & 3.34 & 0.98 & 0.58 \\
1 & -1 & 0.35 & 20.55 & 39.99 & 3.34 & 0.92 & 0.99 \\
1 & -1 & 0.45 & 21.19 & 39.99 & 3.34 & 0.93 & 0.15 \\
\hline
\end{tabular}

\section{Main Notations and Symbols}

$t: \quad$ Index of periods

$i, j$ : Index of retailers

$\mathcal{S}: \quad$ The set of scenarios: $\mathcal{S}=\left\{\xi_{1}, \xi_{2}\right\}$

$\tau: \quad$ Lead time in lateral transshipments

$\varphi_{L}: \quad$ The parameter to determine the magnitude of lateral transshipments

$\theta_{i}$ : The smoothing coefficient in the exponential smoothing algorithm

$\rho_{i}$ : The replenishment parameter to adjust the inventory discrepancy of retailer $i$ in scenario $\xi_{1}$

$\rho$ : The replenishment parameter to adjust systematic inventory discrepancy in scenario $\xi_{2}$

$c_{h}$ : Inventory holding cost per unit

$c_{b}: \quad$ Stock-out cost per unit

$c_{o}$ : Ordering cost per unit

$c_{l}$ : Lateral transshipment cost per unit

$D_{i}(t)$ : The amount of the customer demand of retailer $i$

$I_{i}(t)$ : Inventory level of retailer $i$

$O_{i}(t)$ : The amount of the order placed by retailer $i$

$F_{i}(t)$ : The amount of the demand forecast by retailer $i$

$L_{i}(t)$ : The amount of lateral transshipment received by retailer $i$

BW: Bullwhip effect of the supply chain system

TIC: Average total inventory cost

TOC: Average total ordering cost

LC: Average lateral transshipment cost

$\mathrm{SL}_{i}$ : Customer service level of retailer $i$.

\section{Conflicts of Interest}

The authors declare that there are no conflicts of interest regarding the publication of this article.

\section{Acknowledgments}

This work was supported by the National Natural Science Foundation of China (nos. 71401181, 71701213, and 71501151) and the MOE (Ministry of Education in China) Project of Humanities and Social Sciences (nos. 14YJC630136 and 15YJC630008).

\section{References}

[1] K. Sari, "On the benefits of CPFR and VMI: A comparative simulation study," International Journal of Production Economics, vol. 113, no. 2, pp. 575-586, 2008.

[2] J. G. Szmerekovsky and J. Zhang, "Coordination and adoption of item-level RFID with vendor managed inventory," International Journal of Production Economics, vol. 114, no. 1, pp. 388398, 2008.

[3] C. Paterson, G. Kiesmüller, R. Teunter, and K. Glazebrook, "Inventory models with lateral transshipments: a review," European Journal of Operational Research, vol. 210, no. 2, pp. 125-136, 2011.

[4] H. L. Lee, "A multi-echelon inventory model for repairable items with emergency lateral transshipments," Management Science, vol. 33, no. 10, pp. 1302-1316, 1987.

[5] D. D. Yao, S. X. Zhou, and W. Zhuang, "Joint initial stocking and transshipment - Asymptotics and bounds," Production Engineering Research and Development, vol. 25, no. 2, pp. 273289, 2016.

[6] H. Amrani and E. Khmelnitsky, "Optimal division of inventory between depot and bases," Naval Research Logistics (NRL), vol. 64, no. 1, pp. 3-18, 2017.

[7] K. Glazebrook, C. Paterson, S. Rauscher, and T. Archibald, "Benefits of hybrid lateral transshipments in multi-item inventory systems under periodic replenishment," Production Engineering Research and Development, vol. 24, no. 2, pp. 311-324, 2015.

[8] F. Liu, J.-S. Song, and J. D. Tong, "Building Supply Chain Resilience through Virtual Stockpile Pooling," Production Engineering Research and Development, vol. 25, no. 10, pp. 1745-1762, 2016. 
[9] G. Huang, J. Wang, C. Chen, C. Guo, and B. Zhu, "System resilience enhancement: Smart grid and beyond," Frontiers of Engineering Management, vol. 4, no. 3, p. 271, 2017.

[10] M. G. Avci and H. Selim, "A multi-agent system model for supply chains with lateral preventive transshipments: Application in a multi-national automotive supply chain," Computers in Industry, vol. 82, pp. 28-39, 2016.

[11] L. Tiacci and S. Saetta, "Reducing the mean supply delay of spare parts using lateral transshipments policies," International Journal of Production Economics, vol. 133, no. 1, pp. 182-191, 2011.

[12] B. Satr, S. Savasaneril, and Y. Serin, "Pooling through lateral transshipments in service parts systems," European Journal of Operational Research, vol. 220, no. 2, pp. 370-377, 2012.

[13] K. S. Ramakrishna, M. Sharafali, and Y. . Lim, "A two-item two-warehouse periodic review inventory model with transshipment," Annals of Operations Research, vol. 233, pp. 365-381, 2015.

[14] F. Zhao, D. Wu, L. Liang, and A. Dolgui, "Lateral inventory transshipment problem in online-to-offline supply chain," International Journal of Production Research, vol. 54, no. 7, pp. 19511963, 2016.

[15] G. Yang, R. Dekker, A. F. Gabor, and S. Axsäter, "Service parts inventory control with lateral transshipment and pipeline stockflexibility," International Journal of Production Economics, vol. 142, no. 2, pp. 278-289, 2013.

[16] J. Yang and Z. Qin, "Capacitated production control with virtual lateral transshipments," Operations Research, vol. 55, no. 6, pp. 1104-1119, 2007.

[17] A. H. Tai and W.-K. Ching, "Optimal inventory policy for a Markovian two-echelon system with returns and lateral transshipment," International Journal of Production Economics, vol. 151, pp. 48-55, 2014.

[18] F. Olsson, "Emergency lateral transshipments in a two-location inventory system with positive transshipment leadtimes," European Journal of Operational Research, vol. 242, no. 2, pp. 424433, 2015.

[19] Y. Wang, R. Shou, L. H. Lee, and E. P. Chew, "A case study on sample average approximation method for stochastic supply chain network design problem," Frontiers of Engineering Management, vol. 4, no. 3, p. 338, 2017.

[20] Y. Ouyang and X. Li, "The bullwhip effect in supply chain networks," European Journal of Operational Research, vol. 201, no. 3, pp. 799-810, 2010.

[21] J. Dejonckheere, S. M. Disney, M. R. Lambrecht, and D. R. Towill, "The impact of information enrichment on the Bullwhip effect in supply chains: A control engineering perspective," European Journal of Operational Research, vol. 153, no. 3, pp. 727-750, 2003.

[22] J. Dejonckheere, S. M. Disney, M. R. Lambrecht, and D. R. Towill, "Transfer function analysis of forecasting induced bullwhip in supply chains," International Journal of Production Economics, vol. 78, no. 2, pp. 133-144, 2002.

[23] S. M. Disney and D. R. Towill, "On the bullwhip and inventory variance produced by an ordering policy," Omega, vol. 31, no. 3, pp. 157-167, 2003.

[24] M. Udenio, E. Vatamidou, J. C. Fransoo, and N. Dellaert, "Behavioral causes of the bullwhip effect: An analysis using linear control theory," IISE Transactions, vol. 49, no. 10, pp. 9801000, 2017.

[25] Y. Wei, H. Wang, and C. Qi, "On the stability and bullwhip effect of a production and inventory control system," International Journal of Production Research, vol. 51, no. 1, pp. 154-171, 2013.
[26] S. M. Disney, D. R. Towill, and R. D. H. Warburton, "On the equivalence of control theoretic, differential, and difference equation approaches to modeling supply chains," International Journal of Production Economics, vol. 101, no. 1, pp. 194-208, 2006.

[27] S. M. Disney and D. R. Towill, "A discrete transfer function model to determine the dynamic stability of a vendor managed inventory supply chain," International Journal of Production Research, vol. 40, no. 1, pp. 179-204, 2002.

[28] C. E. Riddalls and S. Bennett, "The stability of supply chains," International Journal of Production Research, vol. 40, no. 2, pp. 459-475, 2002.

[29] H. B. Hwarng and N. Xie, "Understanding supply chain dynamics: a chaos perspective," European Journal of Operational Research, vol. 148, no. 3, pp. 1163-1178, 2007.

[30] Y. Wu and D. Z. Zhang, "Demand fluctuation and chaotic behaviour by interaction between customers and suppliers," International Journal of Production Economics, vol. 107, no. 1, pp. 250-259, 2007.

[31] Y. Wei, H. Wang, and C. Qi, "The impact of stock-dependent demand on supply chain dynamics," Applied Mathematical Modelling: Simulation and Computation for Engineering and Environmental Systems, vol. 37, no. 18-19, pp. 8348-8362, 2013.

[32] F. Chen, A. Federgruen, and Y.-S. Zheng, "Coordination mechanisms for a distribution system with one supplier and multiple retailers," Management Science, vol. 47, no. 5, pp. 693-708, 2001.

[33] S. Axsäter, "Modelling Emergency Lateral Transshipments in Inventory Systems," Management Science, vol. 36, no. 11, pp. 1329-1338, 1990.

[34] S. Zhang, S. Li, S. Zhang, and M. Zhang, "Decision of lead-time compression and stable operation of supply chain," Complexity, Art. ID 7436764, 11 pages, 2017.

[35] S. Zhang, Y. Hou, S. Zhang, and M. Zhang, "Fuzzy control model and simulation for nonlinear supply chain system with lead times," Complexity, Article ID 2017634, Art. ID 2017634, 11 pages, 2017.

[36] F. Chen, Z. Drezner, J. K. Ryan, and D. Simchi-Levi, "Quantifying the bullwhip effect in a simple supply chain: the impact of forecasting, lead times, and information," Management Science, vol. 46, no. 3, pp. 436-443, 2000.

[37] Y. Ouyang and C. Daganzo, "Characterization of the bullwhip effect in linear, time-invariant supply chains: some formulae and tests," Management Science, vol. 52, no. 10, pp. 1544-1556, 2006.

[38] S. M. Disney, "Supply chain aperiodicity, bullwhip and stability analysis with Jury's inners," IMA Journal of Management Mathematics, vol. 19, no. 2, pp. 101-116, 2008.

[39] E. I. Jury, "Theory and Application of the Z-Transform Method," Econometrica, vol. 33, no. 4, p. 884, 1965.

[40] J. W. Brown et al., Complex variables and applications, McGrawHill Higher Education, Boston, USA, 2009.

[41] K. Hoberg, U. W. Thonemann, and J. R. Bradley, "Analyzing the effect of inventory policies on the nonstationary performance with transfer functions," IIE Transactions, vol. 39, no. 9, pp. 911924, 2007.

[42] P. Feng, R. Y. K. Fung, and F. Wu, "Preventive transshipment decisions in a multi-location inventory system with dynamic approach," Computers \& Industrial Engineering, vol. 104, pp. 1-8, 2017.

[43] N. Çömez-Dolgan and B. Tanyeri, "Inventory performance with pooling: Evidence from mergers and acquisitions," International Journal of Production Economics, vol. 168, pp. 331-339, 2015. 


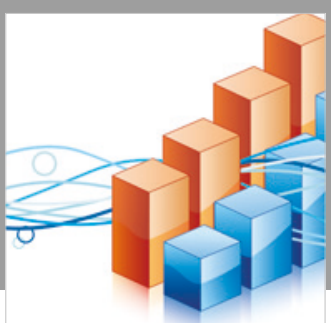

Advances in

Operations Research

\section{-n-m}
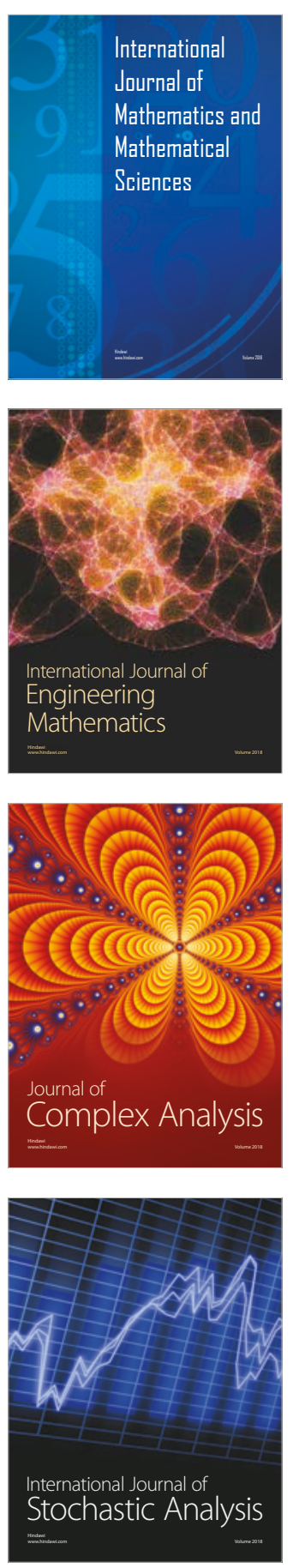
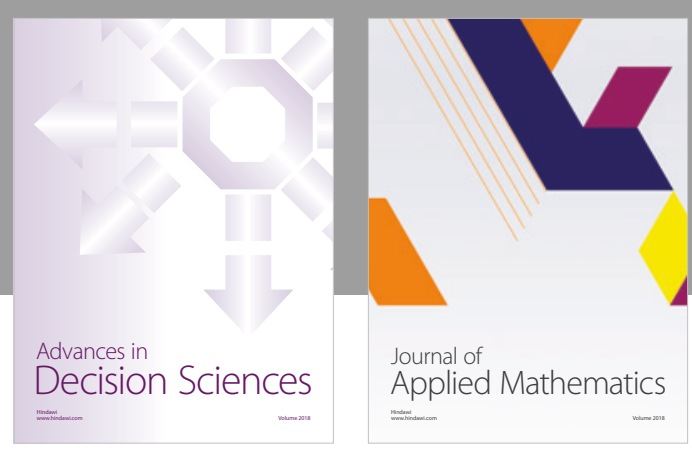

Journal of

Applied Mathematics
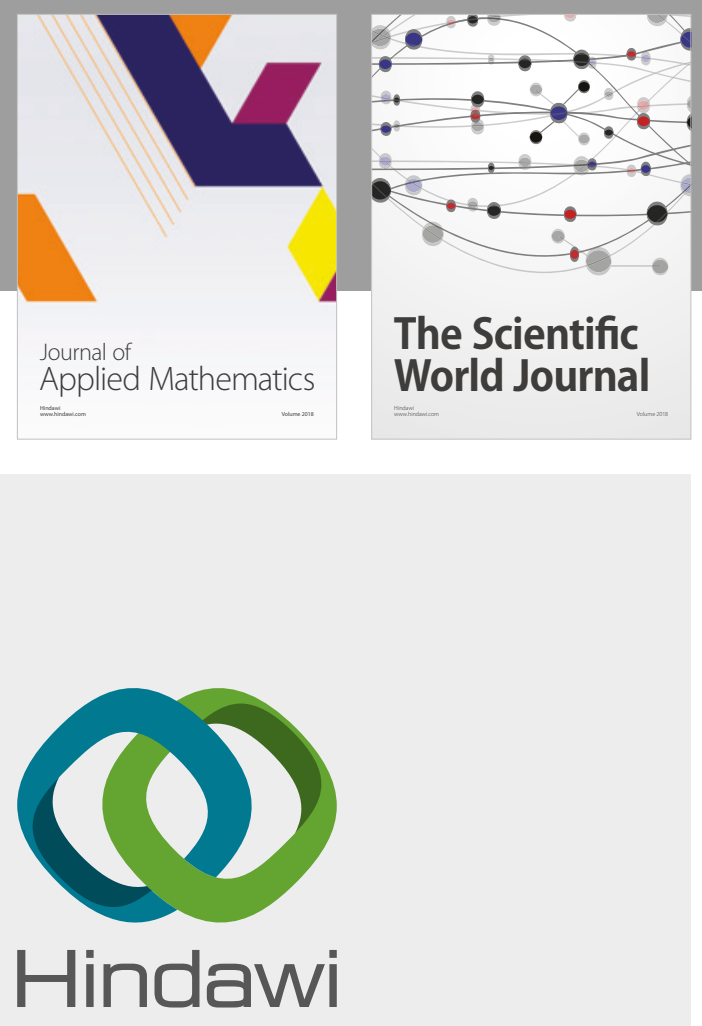

Submit your manuscripts at

www.hindawi.com

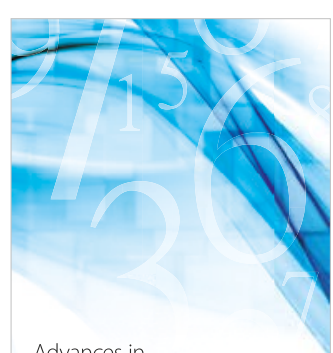

Advances in
Numerical Analysis
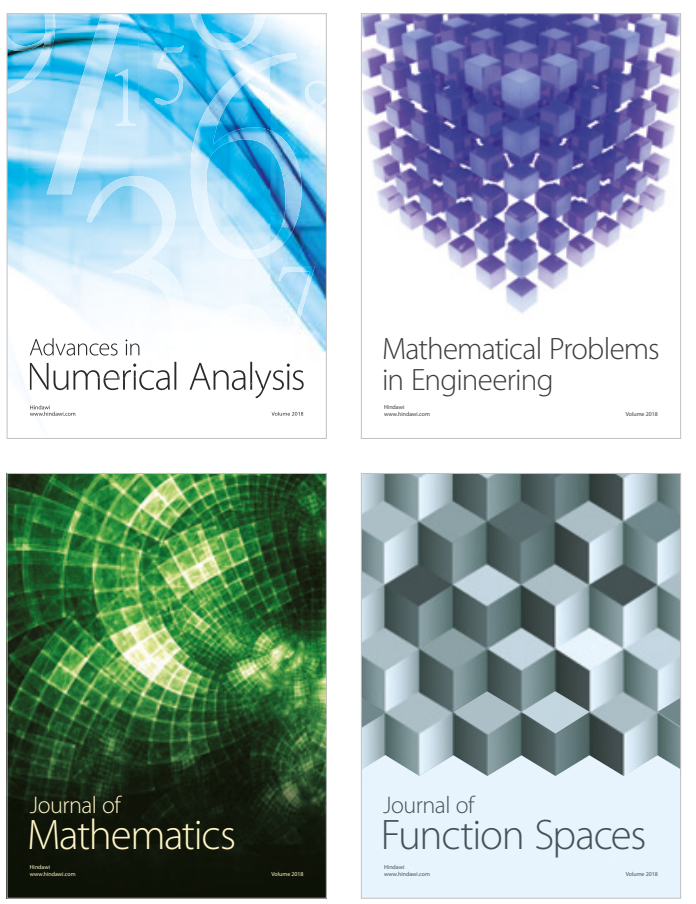

Mathematical Problems in Engineering

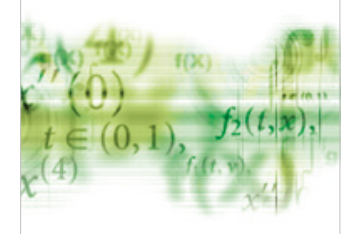

International Journal of

Differential Equations

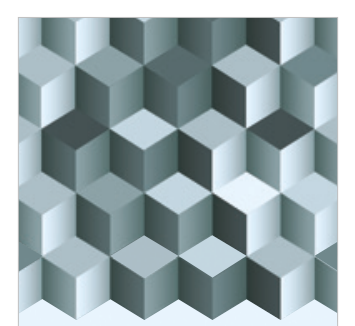

Journal of

Function Spaces
The Scientific

World Journal

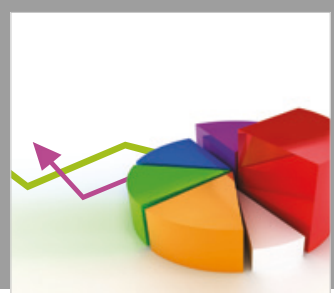

Journal of

Probability and Statistics
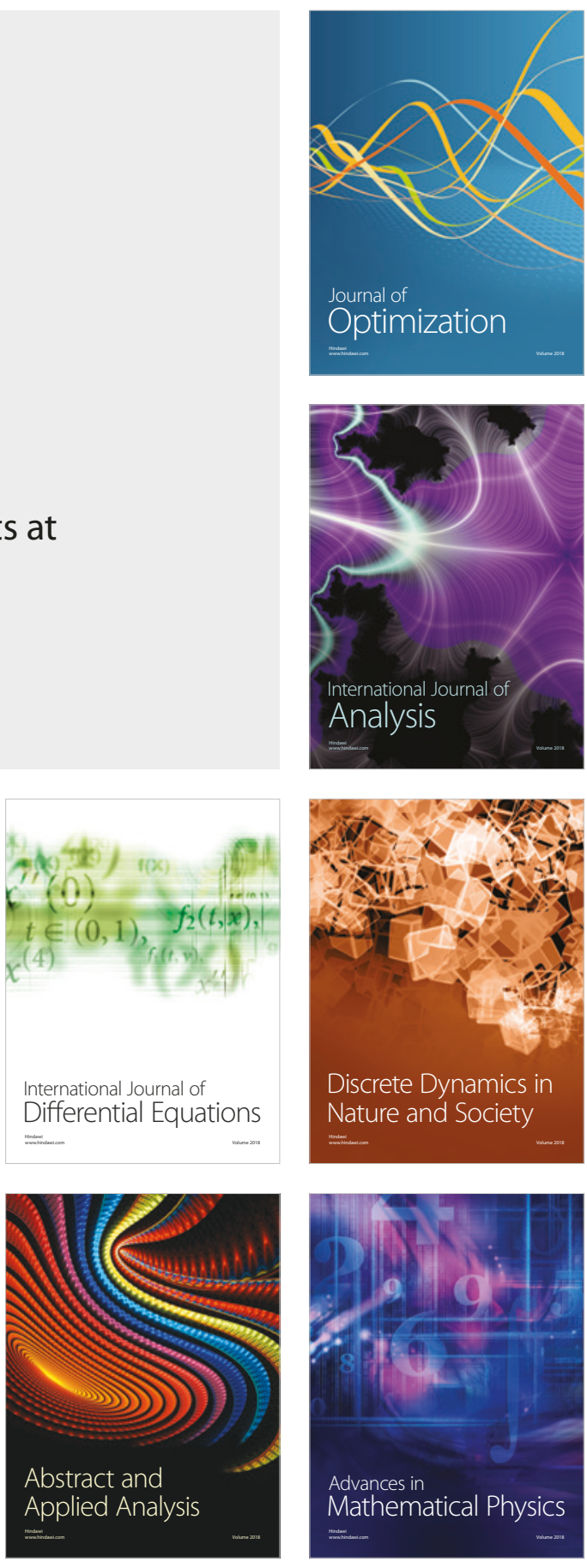